This item was submitted to Loughborough's Research Repository by the author.

Items in Figshare are protected by copyright, with all rights reserved, unless otherwise indicated.

\title{
Modelling and co-simulation of hybrid vehicles: A thermal management perspective
}

PLEASE CITE THE PUBLISHED VERSION

https://doi.org/10.1016/j.applthermaleng.2020.115883

PUBLISHER

Elsevier

VERSION

AM (Accepted Manuscript)

\section{PUBLISHER STATEMENT}

This paper was accepted for publication in the journal Applied Thermal Engineering and the definitive published version is available at https://doi.org/10.1016/j.applthermaleng.2020.115883.

\section{LICENCE}

CC BY-NC-ND 4.0

\section{REPOSITORY RECORD}

Yuan, Ruoyang, Tom Fletcher, Ahmed Ahmedov, Nikolaos Kalantzis, Antonios Pezouvanis, Nilabza Dutta, Andrew Watson, and Kambiz Ebrahimi. 2020. "Modelling and Co-simulation of Hybrid Vehicles: A Thermal Management Perspective". Loughborough University. https://hdl.handle.net/2134/12951542.v1. 


\title{
Modelling and Co-Simulation of Hybrid Vehicles:
}

\section{A Thermal Management Perspective}

\author{
Ruoyang Yuan ${ }^{1 *}$, Tom Fletcher ${ }^{2}$, Ahmed Ahmedov ${ }^{2}$, Nikolaos Kalantzis ${ }^{2}$, Antonios \\ Pezouvanis', Nilabza Dutta ${ }^{3}$, Andrew Watson², and Kambiz Ebrahimi ${ }^{2}$ \\ ${ }^{1}$ School of Mechanical, Electrical and Manufacturing Engineering, Loughborough \\ University \\ ${ }^{2}$ Aeronautical and Automotive Engineering, Loughborough University, \\ 3 Thermal \& Aerodynamic Systems Engineering, Jaguar Land Rover, Gaydon, Warwick \\ * Correspondence: r.yuan@lboro.ac.uk
}

\begin{abstract}
Thermal management plays a vital role in the modern vehicle design and delivery. It enables the thermal analysis and optimisation of energy distribution to improve performance, increase efficiency and reduce emissions. Due to the complexity of the overall vehicle system, it is necessary to use a combination of simulation tools. Therefore, the co-simulation is at the centre of the design and analysis of electric, hybrid vehicles. For a holistic vehicle simulation to be realized, the simulation environment must support many physical domains. In this paper, a wide variety of system designs for modelling vehicle thermal performance are reviewed, providing an overview of necessary considerations for developing a cost-effective tool to evaluate fuel consumption and emissions across dynamic drive-cycles and under a range of weather conditions. The virtual models reviewed in this paper provide tools for component-level, system-level and control design, analysis, and optimisation. This paper concerns the latest techniques for an overall vehicle model development and software integration of multi-domain subsystems from a thermal management view and discusses the challenges presented for future studies.
\end{abstract}

Keywords: thermal energy; multi-disciplinary optimisation; holistic vehicle model; cosimulation. 


\section{Highlights:}

- Overviews the current developments in modelling tools for thermal management of hybrid vehicles

- Co-simulation enables whole vehicle model architecture development with reduced costs

- Thermal subsystem model and optimisation further request the development of fast running models

- Heat retention modelling work shows effectively reducing CO2 emissions and $2.5 \%$ fuel savings 


\section{Table of Contents}

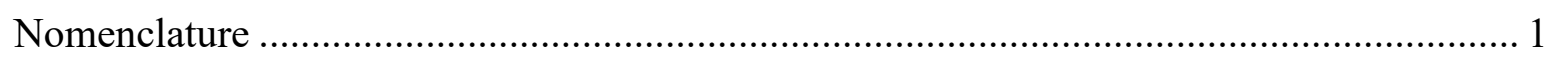

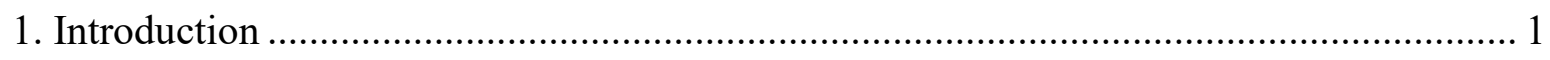

The role of modelling and simulation in the modern vehicle design ............................. 1

Thermal management of hybrid vehicles ..................................................................... 2

Model development and co-simulation approach ................................................... 3

Previous reviews and focus of this work .................................................................... 5

2. Hybrid Vehicle Powertrain Model ........................................................................... 6

Current development in vehicle powertrain models.................................................... 6

Application to legislative drive cycles' simulations...................................................... 1

New aspects for the powertrain modelling ............................................................... 2

Development of the powertrain warm-up simulation.................................................... 3

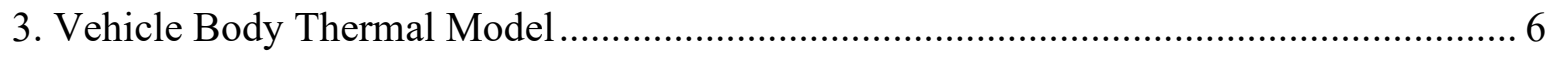

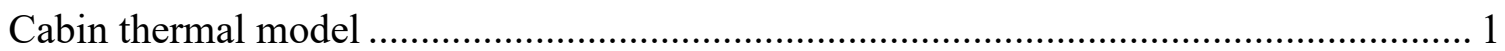

Link with the vehicle heating ventilation and air-conditioning system ........................... 1

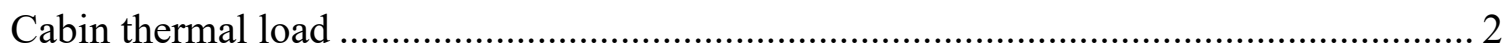

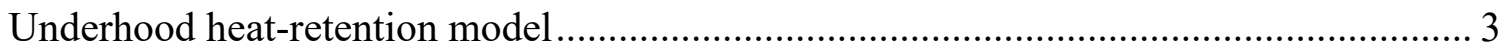

Benefits for $\mathrm{CO}_{2}$ emissions and fuel economy....................................................... 6

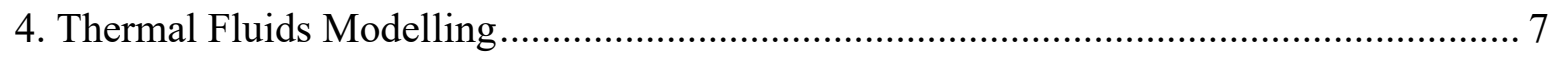

High Temperature Coolant Circuit (powertrain cooling) ............................................. 9

Low Temperature Coolant Circuit (power electronics, motors, batteries' cooling) .......... 9

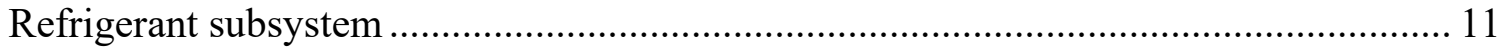

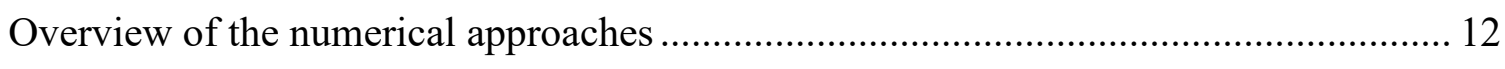

5. Model architecture and Co-Simulation Methodology …........................................... 14

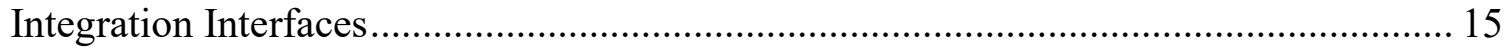

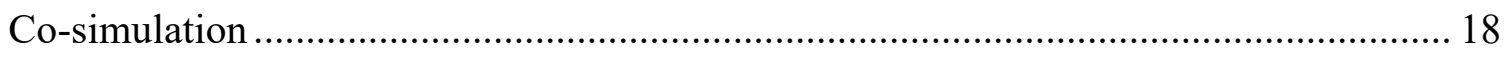

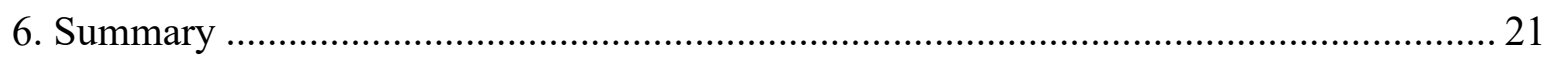

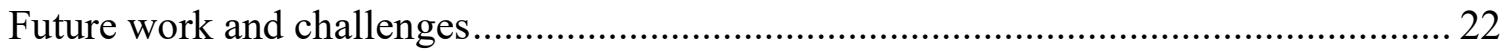

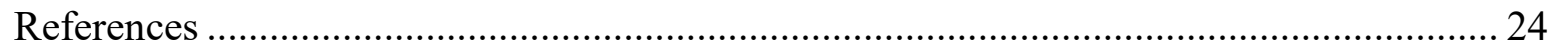




\section{Nomenclature}

ABS anti-lock braking system

AC air-conditioning

AFR air fuel ratio

ANN artificial neural network

BCU battery control unit

BEV battery electric vehicle

BISG belt-integrated starter generator

CAE computer aided engineering

CFD computational fluid dynamics

CISG crank-integrated starter generator

CIMG crank integrated motor generator

CS co-simulation

CVT continuously variable transmission

ECU engine control unit

EMS energy management system

FMI functional mock-up interface

FMU functional mock-up unit

FPGA field-programmable gate array

FRM fast running model

HTC heat transfer coefficient

HVAC heating ventilation and air-conditioning

LBM Lattice-Boltzmann method

ICE internal combustion engine

ICOS Linux based network operating system

IHE internal heat exchanger

TXV thermostatic expansion valves

ME model exchange

MiL model in loop

NEDC new European drive cycle

OEM original equipment manufacturer 
PHEV plug-in hybrid electric vehicle

PTC positive temperature coefficient

RDE real driving emissions

S2S surface-to-surface

TMS thermal management system

VCI vehicle communication interface

VDC vehicle dynamics controller

VHDL VHSIC hardware description language

VHSIC very high-speed integrated circuit

VSC vehicle supervisory control

WLTP worldwide harmonised light vehicle test procedure

g the acceleration due to gravity

$k \quad$ thermal conductivity

$\beta \quad$ thermal expansion coefficient

$\rho \quad$ density

$L \quad$ representative dimension

$\Delta \mathrm{T} \quad$ temperature difference

$v \quad$ kinematic viscosity

$\varepsilon \quad$ internal energy density

$\vec{u} \quad$ velocity vector

$f \quad$ particle number density

$t \quad$ time

$\vec{x} \quad$ position

$q \quad$ heat flux

Gr Grashof number

$\mathrm{Nu} \quad$ Nusselt number

Pr Prandtl number

Ra Rayleigh number 


\section{Introduction}

The role of modelling and simulation in the modern vehicle design

Computer Aided Engineering (CAE) holds a central position in modern automotive development and testing, which has allowed engineers to create and simulate virtual representations of physical systems [1] and make observations which are applicable in the physical world. As a result, better designs of components and systems can be achieved while the need for physical prototypes is reduced [2,3]. For example, Figure 1 draws a CAE design iteration diagram of a vehicle: it starts from overall system specifications, followed by virtual system development, component subsystem testing, powertrain simulation, and finishing with model validation and optimisation. At each stage, early results feedback to the previous stage to refine the development. Different departments tend to use application-specific modelling environments across the vehicle development cycle $[1,4]$. As a result, components of a system are designed in relative isolation from one another $[3,5,6]$ which can lead to integration issues [2], and often duplication of work.

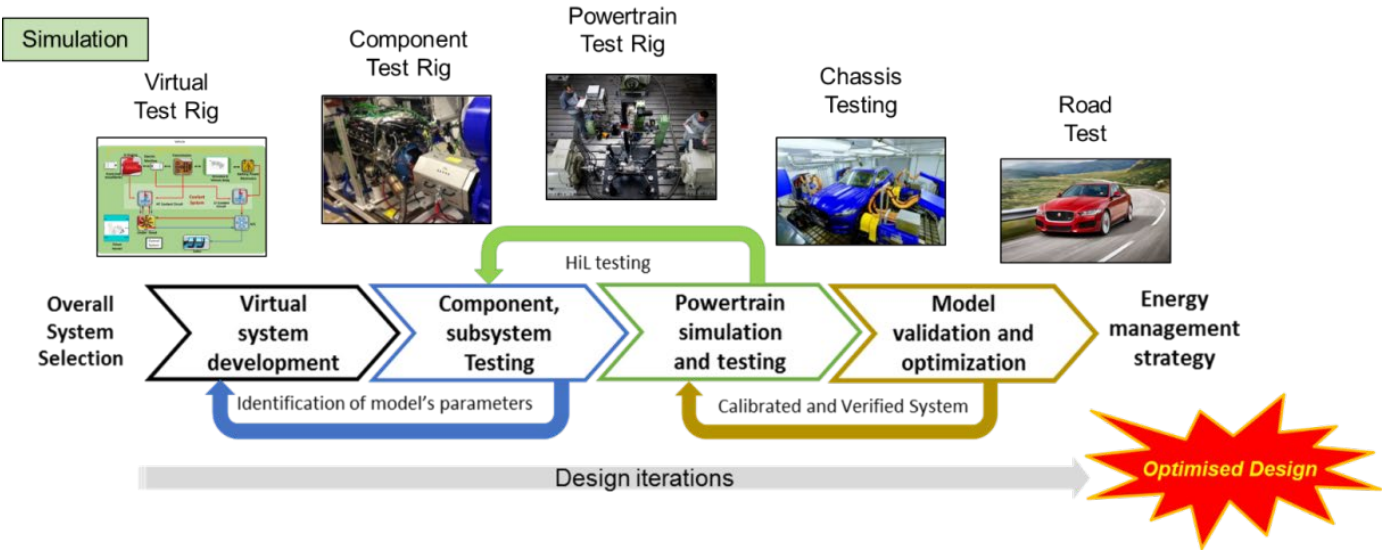

Figure 1. CAE design process of modern vehicles to help obtain the optimum energy management strategy.

A collection of components designed independently does not necessarily constitute an overall optimal system design. True system performance is often only evaluated and validated once a physical prototype of the system is available for testing, thus leaving design defects to be detected at later stages of system development and increasing development costs significantly [3,6].

Another disadvantage of the traditional design method is its non-flexible sequential nature of design flow. The modern approach in vehicle systems design involves taking 
advantage of the connectivity of the different application-specific CAE environments, used throughout an automotive company, to set up a holistic vehicle simulation. This takes into account the effect of the interaction between components in system performance and robustness, thus enabling the engineers to carry out a system design validation within their preferred software, and at an early design stage by following a synergistic component design flow. Such an approach allows for confident design validation at an early stage and the realization of truly optimal system designs not possible under the sequential system design. Design defects are detected early in the development cycle and as a result, most design revisions take place prior to the commissioning of a physical prototype thus reducing development costs and contributing to more robust products $[3,6,7]$. As such, a holistic vehicle simulation allows for concurrent development and testing of components and control code thus reducing the development duration [5,8-10]. One of the areas in which the holistic vehicle simulation approach is most significant is in thermal analysis and management, which has become an integral part of modern hybrid vehicle design and delivery.

The following sections will address the importance and discuss the latest model development for the thermal management of hybrid vehicles, which is the focus of this review. This paper does not consider a single hybrid architecture in particular, but instead will highlight differences between micro/mild/full hybrids where appropriate.

\section{Thermal management of hybrid vehicles}

There has been significant attention on the thermal management on electric hybrid vehicles focusing solely on the batteries thermal management [11-14] and associated safety concerns [15]. Since the performance and life of most commonly used batteries are sensitive to temperature, so a battery thermal management system is required to effectively balance the heat generated during the battery charging and discharging process in order to maintain its operating temperatures and ensure the uniform distribution of temperatures across the battery unit. Active and passive cooling methods with air, liquid, and phase change material [15], as well as emerging techniques ideas such as thermoelectric cooler, thermo-acoustic and magnetic refrigeration [16] are addressed in 
detail in the recent reviews [11-13,15,16], and although covered briefly, they are therefore not the focus of this review.

Instead, we consider two other important aspects to consider from a thermal management perspective of hybrid vehicles: the heat balance and integrated thermal energy efficiency associated with both mechanical and electrical components of powertrain, and the thermal management associated with the climate control of the cabin. Optimised thermal management allows hybrid vehicles to achieve improved performance, increased efficiency, and a reduction in emissions by optimising heat balance of the engine, transmission, battery, and motor temperatures, while maintaining fast full-climate control of the cabin. However, simultaneous thermal management of the above vehicle components requires an elevated level of communication between the respective component design teams who will each have their own software packages and methodologies suitable for their particular component.

\section{Model development and co-simulation approach}

The simulations of the previously mentioned various vehicle thermal aspects usually target the optimisation of the component level efficiency but are not able to predict how the overall vehicle efficiency will be affected with much accuracy. For instance, battery thermal models coupling electrochemical models with thermal models were developed [17-19] to simulate the heat generation and the energy balance in detail, however, this tends to be isolated from interactions with other thermal attributes of the vehicle. Vehicle and powertrain models [20] tend to focus on the evaluation of mechanical components over various legislative drive-cycles, using simplified lumped masses to simulate component warm-up and its subsequent effect on engine and transmission efficiency. They also tend to neglect details such as the climate control of the cabin entirely. Engine modelling techniques tend to focus on steady-state mapping points but may use simplified vehicle and transmission models for optimisation over similar drive-cycles, duplicating the work of the powertrain models, but allowing more detailed analysis of the engine behaviour. Heating, Ventilation, and Air Conditioning (HVAC) system models tend to simulate thermal fluids in heating circuits and refrigerant loops, using a 1D and 3D fluid modelling approach to simulate and evaluate performance [21-23]. Finally, under-hood heat retention modelling and its potential $\mathrm{CO}_{2}$ emissions benefits may be studied using 
combined low-order modelling and high-fidelity computational fluid dynamics (CFD) [24-28]. As the different vehicle subsystems are developed and tested under applicationspecific modelling and simulation environments, the effect component interaction has on system level either requires the duplication of work or is neglected entirely. However, it should be considered in order to reduce development costs and duration, and to improve overall system design [29-31].

An example of an integrated vehicle thermal model diagram is shown in Figure 2, consisting of vehicle powertrain model, thermal fluids, and vehicle body subsystems. (1) The powertrain subsystem consists of IC engine, transmission, electrical drive system (motor, battery pack, inverter) and driveline models, discussed below in section 2. The powertrain subsystem models the dynamic characteristics such as engine and transmission warm-up, engine stop-start, and gearshifts and outputs the overall vehicle performance over legislative and real-world driving cycles. The powertrain subsystem is primarily concerned with the mechanical and electrical domains, but also contains all control logic. (2) The thermal fluids subsystem, discussed in section 3, models the performance of the thermal fluids within the different cooling systems, such as a vehicle HVAC system, powertrain cooling system, and cabin thermal system. The thermal fluids subsystem focusses on 1D hydraulic and thermal modelling providing temperature information to the vehicle model and receiving heat rejection data as feedback. (3) The vehicle body subsystems include the cabin and the under-hood models. The former models the climate control of the cabin and the latter models the cool-down and heat retention behaviours of vehicle engine bay compartments during vehicle static soak to provide predictions of engine structure, coolant and oil, and transmission structure and oil temperatures while the vehicle is stationary. The fluid temperatures predicted from the heat retention model are fed back to the powertrain and thermal fluids models as initial conditions. The underhood model can be a detailed 3D Computational Fluid Dynamics (CFD) model running sequentially with the rest of the model. 


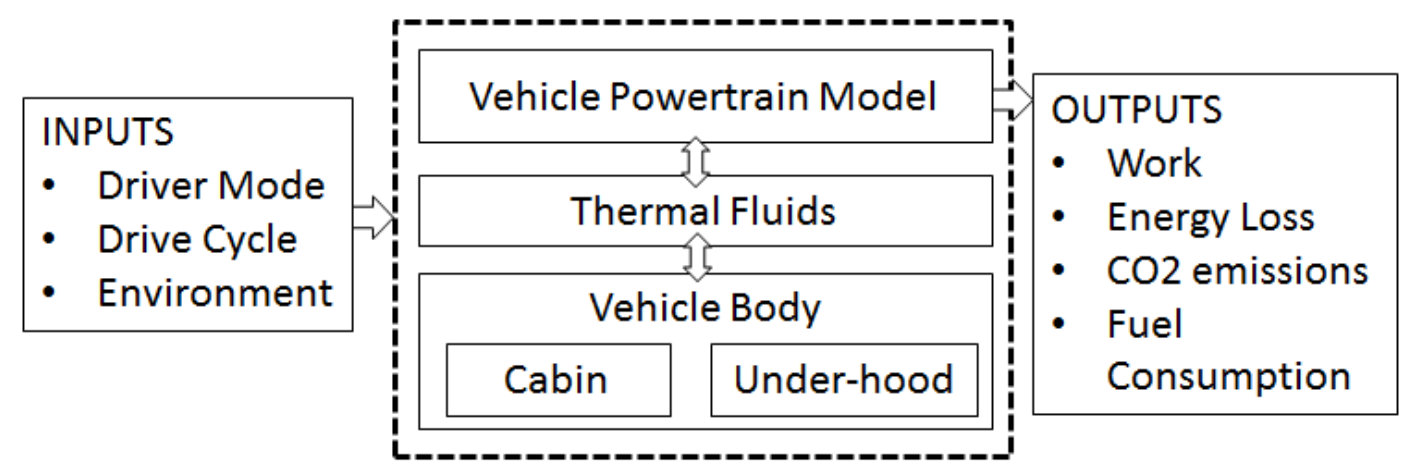

Figure 2. Integrated vehicle thermal model

Previous reviews and focus of this work

Several existing reviews already covered for the thermal management of individual components such as the battery [11-16], vehicle cabin [32] and for the control strategies of hybrid vehicles [33]. However, there is a lack of review on the thermal management of the hybrid vehicle as a whole system, especially from a modelling approach. The thermal performances of the vehicle powertrain, battery unit and the cabin are highly interdependent and should not be isolated for the evaluation. The platform to support the co-simulation and its efficiency need to be addressed. This paper therefore aims to provide an overview of the existing methods and the modelling tools used for the thermal energy management of hybrid vehicles, with a particular focus on the requirement for holistic vehicle modelling.

The remainder of this paper is organised as follows; Section 2 examines the latest techniques for vehicle powertrain modelling, particularly looking at the effect of engine and transmission warm-up on fuel consumption and emissions over legislative and realworld driving scenarios. Section 3 focusses on under-hood heat retention modelling, a comparatively new area of research with the possibility of reducing real-world emissions significantly by reducing the number of cold starts. Section 4 describes methodologies for vehicle thermal fluids, including models of liquid cooling circuits, multi-phase refrigerant circuits and cabin modelling. Section 5 reviews holistic modelling and co-simulation techniques which can be used to simulate multi-domain problems such as thermal energy management in a hybrid vehicle. 


\section{Hybrid Vehicle Powertrain Model}

High-level vehicle attributes such as fuel consumption, emissions, and battery utilization are predicted using vehicle powertrain models by simultaneously evaluating hydraulic, thermal, mechanical, and electrical vehicle subsystems. Figure 3 shows an example of a hybrid vehicle powertrain model layout. The co-simulation add-on in the figure refers to the possible capability of integrating various subsystem models developed in separate platforms, which will be discussed in section 5. In this section we discuss the realisation of vehicle powertrain model to simulate the mechanical and electrical vehicle subsystems for legislative [34-36] and other drive-cycles in order to calculate high-level vehicle attributes such as fuel consumption [37,38], emissions [39], and battery utilization [40].

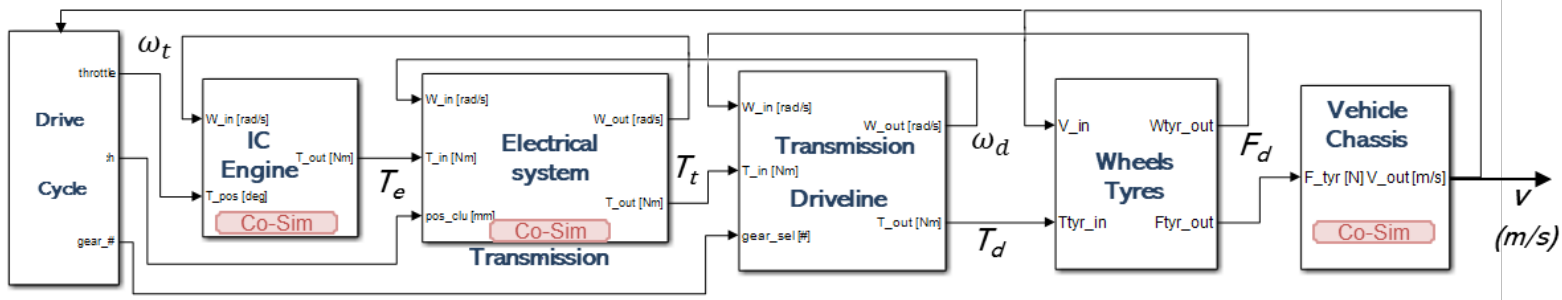

Figure 3. Powertrain Model

\section{Current development in vehicle powertrain models}

Vehicle powertrain models typically simulate longitudinal motion of the vehicle using a vehicle speed reference which varies over time. This reference can be a legislative drivecycle $[41,42]$, real world logged data $[43,44]$ or custom traces to simulate particular conditions such as vehicle acceleration or gradeability tests $[45,46]$. Vehicle powertrain models are generally separated into three categories; backward facing $[47,48]$, forward facing [49-51] and acausal models [52-54].

Backward facing models assume that the vehicle follows the reference speed perfectly [55] and calculates the force required to do this using a model of the vehicle drag [56]. The tractive force and speed of the vehicle is then used to calculate the wheel speed and torque [57], and the information flows backwards through the model to calculate the required engine torque and speed which are then used to estimate the fuel consumption and 
emissions [58]. Because the vehicle speed is directly imposed and the required torque is calculated from the imposed speed, these models are also commonly referred to as kinematic models $[59,60]$. The advantage of this type of model is that they are relatively simple [61], and fast running [62,63].

Forward facing models are more representative of what happens in the real world [61,64]. A driver model (usually Proportional-Integral (PI) control based [64]) uses the vehicle speed reference and feedback from the modelled vehicle speed to control the torque demand of the engine (and the demands to the brakes and clutch). The engine responds by outputting a torque which flows forward through the transmission, driveline and wheels to produce a tractive force which causes the vehicle to accelerate (after accounting for losses in the driveline and the drag due to aerodynamics, etc.). For this reason, forward-facing vehicle powertrain models may also be referred to as "Dynamic" models [60]. Then, as with the backward facing model, the resultant vehicle speed is passed backwards through the driveline to ultimately define the engine speed [55]. The torque and speed of the engine can then be used to estimate fuel consumption, emissions etc.. Although forward facing models are more representative of the real world, they can produce less reliable results [55]. This is because the coupling between speed and torque, flowing in opposite directions through the powertrain model, usually requires much smaller sample times to ensure stability. Additionally, the requirement to tune the driver model greatly increases the complexity. Different models or settings for the driver can significantly affect the results [51]. 
Acausal models are neither inherently backward facing, nor forward facing because the causality is only defined when they are initialized before simulation. They work by using a physically orientated modelling approach describing the system using physical equations and interfaces [52]. For example, an electrical interface will consist of numerical connections for both voltage and current. Each of these connections can be either inputs or outputs to the component depending on the flow of information in the system as a whole. This allows the same basic model to be used for both forward-facing and backward-facing simulations depending on the inputs given [54]. Acausal models tend to be slightly more complex and time-consuming to develop and validate, but there are a number of software packages such as openModelica [54,55], Dymola [52,53,65], Simscape Driveline [52], and AMESim [66-68] which are available with pre-defined interfaces, component models, and even example systems to alleviate this issue. The major advantage of this type of model is that systems and components can be re-used much more readily and for many different purposes.

\section{Application to legislative drive cycles' simulations}

Traditionally, backward-facing simulation has dominated powertrain model development due to its faster speed and highly repeatable results. This has made it suitable for large-scale Design of Experiment (DoE) and optimisation tasks which are common tasks for systems integration and Vehicle Supervisory Control (VSC) development $[49,55,69]$. However, in recent years, legislative changes, particularly the introduction of the Worldwide Light Transport test Protocol (WLTP) and Real Driving Emissions (RDE), has pushed researchers to focus more on forward-facing and acausal approaches. This is because highly dynamic drive-cycles are more sensitive to the drivervehicle interaction and therefore it has become much more important to capture the driver behaviour within the simulation model [70]. This has also led to significant volumes of research into driver models [71], particularly incorporating model-based feed-forward control and "look ahead" functionality [72]. Backward-facing models are still relevant, however, because they can be used to "play-back" logged data precisely, where the driver behaviour is captured within the reference vehicle speed [55]. 
New aspects for the powertrain modelling

The highly dynamic properties of the WLTP and RDE tests have also driven further innovation in powertrain modelling [36]. Historically, vehicle powertrain models would consistent of relatively simplistic models (e.g., mapped engines [73]) so that they can be quickly created, parameterized, validated and simulated in a variety of configurations for component sizing and control optimisation exercises [74-76]. However, dynamic characteristics of the engine response have become much more important due to the events such as engine and transmission warm-up [53,77,78], engine stop-start $[79,80]$, tipin [81], and power-on gearshifts occurring more frequently during the tests. These events can account for a substantial proportion of the emissions if not properly managed by the powertrain and vehicle supervisory control modules and therefore it is vital to include them in the vehicle powertrain model by using more advanced component models [78]. These types of models also tend to require a forward facing or acausal modelling approach due to their dynamic nature.

Added to this increasing complexity of powertrain is the introduction of electric machines in vehicle powertrains, from mild hybrids to fully electric vehicles. With the intensified effort to reduce emissions most OEM's are now continually increasing the level of electrification to some degree. Mild hybrid vehicles can be as simple as employing a belt-integrated starter generator (BISG), replacing traditional alternator and conventional starter motor [82]. These powertrain designs usually help through automated engine stopstart and kinetic energy recovery through regenerative braking [82,83]. Thermal management of these BISG's are usually air-cooled solutions [84]. Modelling of the propulsion system for BISG mild hybrid vehicle can be limited to forward facing or acausal modelling approaches due to the relevance of thermal management noise factors being very limited [85]. With increasing level of electrification many OEM's are moving towards a crank-integrated starter generator (CISG) [85]. These CISG propulsion systems employ an electric machine which are generally thermally managed by water or oil [86]. CISG propulsion systems provide the vehicles with increased capacity of torque to supplement the internal combustion engine and also a degree of electric-only driving at extremely low vehicle speeds or engine off coasting [86]. CISGs also offer the vehicle a greater flexibility of increased engine-off idling due to migration of higher electrical loads 
to the alternate electric systems in the car [86]. Modelling of CISG propulsion system can be managed solely within the electrical energy domain or may need to employ cosimulations for modelling the efficiency change of such electrical machines due to its thermal management, as discussed later in this review paper $[87,88]$.

As the level of electrification of vehicle increases towards full hybridisation (both plug in and non-plug in versions) the type of electrical machine changes from CISG to crank integrated motor generator (CIMG). The electric and thermal behaviour are significantly more challenging to model due to the increased level of kinetic energy regeneration, increased function of providing vehicle propulsion in fully electric drive and the migration to higher voltage levels to provide the necessary power required for vehicle propulsion [8]. The control system modelling of this type of propulsion system is also increasingly challenging due to the increased level of complexity of providing power to wheel in internal combustion engine only, combination of internal combustion \& electric and electric only energy source [83,87-90].

As vehicles become more efficient, there is less wasted heat from the powertrain available for powertrain warm-up and cabin climatic control. As a result, it is becoming increasingly important to include previously neglected systems such as the powertrain cooling circuit and cabin environment in the design of the vehicle model [91,92]. This issue is compounded in fully electric vehicles which are already subjected to constraints on the available stored energy. For example, in Battery Electric Vehicles (BEVs), the load generated by the HVAC system can significantly affect the vehicle's range $[93,94]$.

\section{Development of the powertrain warm-up simulation}

Legislative emissions tests often require starting the vehicle from "cold" [95]. This typically means that the vehicle is required to stand in a pre-conditioning chamber for a period of time at a fixed initial temperature to allow the engine, transmission, fluids and catalyst to settle to this initial temperature. For vehicles sold in the EU this initial temperature is $14^{\circ} \mathrm{C}$ [34], which represents the annual average temperature across the EU, and the vehicle must be kept at this temperature for a minimum of 24 hours before the engine is started. Internal combustion engines operate most efficiently at $90-100^{\circ} \mathrm{C}$ and therefore, this is the temperature range to which they are controlled during normal 
operation. The period of time after engine start-up and before the engine and transmission have reached normal operating temperature is referred to as the "warm-up period".

The warm-up period in particular can account for a considerable proportion of the engine emissions, mainly due to increased friction in the engine and transmission as the result of low oil temperatures and poor emissions aftertreatment due to low catalyst temperatures [96]. Additionally, lambda sensors also require heating before they produce fast and accurate results [97] so there is usually a period of time after engine start up where the air-fuel ratio is controlled without feedback from the lambda sensor (open loop Air Fuel Ratio, AFR) which itself can result in increased fuel consumption and high levels of emissions. For Hybrid Electric Vehicles (HEVs) which can run without the engine started, it is also possible for the catalyst temperature to drop below the light-off temperature during a journey [97].

At the systems level, engine and transmission warm-up is usually captured using simplistic lumped mass models based on empirical data. These models can be quickly and easily tuned to match experimental results, but due to their simplicity and reliance on empirical data they are not very useful for assessing design changes to the fluid circuits and/or engine control strategy. This issue is exacerbated by the fact that experimental testing of the engine warm-up is a very time-consuming and expensive process due to the fact that the vehicle must be allowed to cool back to ambient temperature in between each test [98]. As a result, it is typically only possible to perform a maximum of 4 warm-up tests per vehicle per day.

One way of alleviating this issue is through experimental techniques such as rapid cooldown. Rapid cool-down involves externally chilling powertrain fluids and circulating them through the powertrain to cool the engine and transmission structure. At the same time, air is passed through the exhaust to cool the catalytic converter and lambda sensor. Using rapid cool-down has allowed automotive Original Equipment Manufacturers (OEMs) to perform 13-17 warm-up tests in a 24-hour period [99], however care must be taken to ensure that all latent heat has been extracted and that the vehicle has not been modified significantly to allow this process to be performed. It should also be mentioned that forced induction of fresh air over the catalyst may also affect its absorbed oxygen state [100], and potentially resulting in bias to the results. 
In contrast, simulation is highly suitable for assessing the effect of design and control strategy changes during warm-up. This is because the simulation can be started from the exact same conditions every time, producing much more repeatable results [101]. Additionally, simulation offers the advantage that the component prototypes do not need to be produced physically in order to be tested [101]. However, this requires much more detailed models of the thermal management components than the traditional lumped mass approach [91].

One way to achieve this is to use a 1D fluid modelling approach incorporating the major components in the engine coolant path. This already is typically performed by component design teams using software such as Dymola [53], KULI [102,103] or GT Suite [104,105]. In this way, the system dynamics of the coolant fluid flow and heat transfer paths can be captured in higher detail because these models are based on physical characteristics of the cooling circuit components. However, these models tend to be relatively slow to simulate over legislative duty cycles; taking in the order of around 5 hours in order to simulate the approx. 30-minute WLTC [106]. This makes them unsuitable for system-level evaluations of the effect of component sizing DoE, and control strategy optimisation without using advanced simulation techniques such as model reduction [92], surrogate models and cosimulation $[53,107]$.

There is also a significant volume of work modelling of the oil circuit in the literature. This work involves modelling the friction in both the engine [92,108] and transmission incorporating things such as bearing friction models [109], pistons liner contact [110], valvetrain lubrication, friction in the gear mesh [111], torque converter efficiency and torque losses due to pumping requirements. These models tend to use similar methodology to the coolant circuit with the added complexity that the relevant properties of the oil, such as viscosity, are much more variable with temperature [112].

In addition to the ICE, there has been considerable work on the thermal management of batteries $[11,13,16,113]$ and the modelling on batteries performances $[12,14,15]$, including detailed electrochemical modelling of batteries internal reactions and the heat generation, the external battery cooling modelling focusing on the heat removal process and the uniformity of the temperature distributions of the batteries [15]. Various battery thermal management models are discussed in detail in the following reviews [15,113]. 
More advanced warm-up models incorporate 3D models of various components coupled with the 1D coolant or oil circuits. These models typically use computational fluid dynamic (CFD) models of major fluid pathways such as the engine coolant jacket [114], oil sump [112] or radiator, of air pathways such as an engine under-hood model [25,115], and/or finite element models of the solid engine structure [116] and/or battery [117]. Unfortunately, these models tend to be much slower to simulate than 1D or lumped mass models and are therefore not typically suitable for evaluating a large number of design or control strategy modifications using co-simulation.

A summary of the current powertrain simulation techniques is shown in Table 1.

Table 1 - Summary of Powertrain Simulation Techniques

\begin{tabular}{|l|l|l|l|}
\hline Technique & Examples & Advantages & Disadvantages \\
\hline Backward facing & $\begin{array}{l}{[47,48,56-} \\
63]\end{array}$ & $\begin{array}{l}\text { Easy to implement, fast } \\
\text { simulation, repeatable results }\end{array}$ & $\begin{array}{l}\text { Quasi-steady state, no driver } \\
\text { behaviour, control strategy } \\
\text { neglected/simplified }\end{array}$ \\
\hline Forward facing & {$[49-51,64]$} & $\begin{array}{l}\text { Suitable for highly dynamic } \\
\text { cycles or real-world driving, } \\
\text { easy to implement }\end{array}$ & $\begin{array}{l}\text { Slower to simulate than above, } \\
\text { less repeatable, highly sensitive } \\
\text { to driver model, control strategy }\end{array}$ \\
\hline Acausal & $\begin{array}{l}{[52-55,65-} \\
68]\end{array}$ & $\begin{array}{l}\text { Same model can be used for } \\
\text { forward/backward facing } \\
\text { simulations }\end{array}$ & $\begin{array}{l}\text { Requires acausal simulation } \\
\text { software (SimScape/Modellica) }\end{array}$ \\
\hline Co-Simulation & $\begin{array}{l}{[28,53,102-} \\
105]\end{array}$ & $\begin{array}{l}\text { Suitable for multi-domain } \\
\text { simulation, high fidelity } \\
\text { results }\end{array}$ & $\begin{array}{l}\text { Slowest to simulate, high model } \\
\text { development effort, }\end{array}$ \\
\hline
\end{tabular}

\section{Vehicle Body Thermal Model}

The vehicle body thermal model consists of the cabin thermal model and under-hood heat retention model. Table 2 summarizes the main simulation methods of the vehicle body thermal model and their relative advantages and disadvantages. 
Table 2 - Summary of vehicle body thermal modelling methods

\begin{tabular}{|c|c|c|c|}
\hline Model output & Modelling method & Advantages & Disadvantages \\
\hline \multirow[t]{4}{*}{$\begin{array}{l}\text { Vehicle Cabin } \\
\text { Compartment } \\
\text { Thermal Load }\end{array}$} & Data-driven (empirical) $[21,119]$ & $\begin{array}{l}\text { Simple, allows for real time modelling and control } \\
\text { applications }\end{array}$ & $\begin{array}{l}\text { Compromised prediction accuracy, can give unrealistic } \\
\text { output, dependent on test data, performance } \\
\text { prediction stability problems }\end{array}$ \\
\hline & $\begin{array}{l}\text { Steady State Physics-based } \\
\text { (mathematical) }[23,124,125, \\
148]\end{array}$ & $\begin{array}{l}\text { Relatively simple, close representation of the } \\
\text { modelled system }\end{array}$ & $\begin{array}{l}\text { Iterative processing needed, in depth knowledge of the } \\
\text { system and the involved processes }\end{array}$ \\
\hline & $\begin{array}{l}\text { Dynamic Physics-based } \\
\text { (mathematical) [22, } 28 \text { 120-122, } \\
126,150]\end{array}$ & $\begin{array}{l}\text { High fidelity, close representation of the modelled } \\
\text { system }\end{array}$ & $\begin{array}{l}\text { Complex, Iterative processing needed, in depth } \\
\text { knowledge of the system and the involved processes, } \\
\text { compromised flexibility }\end{array}$ \\
\hline & Finite volume method $[170,171]$ & High fidelity, accurate numerical predictions & $\begin{array}{l}\text { Computationally demanding, slow, not suitable for } \\
\text { fast response modelling in vehicle thermal load } \\
\text { fluctuations }\end{array}$ \\
\hline $\begin{array}{l}\text { Underhood } \\
\text { heat-retention } \\
\text { model [24-28, } \\
112,131]\end{array}$ & $\begin{array}{l}\text { Steady 3D CFD method [24] / } \\
\text { coupled 1D - 3D transient } \\
\text { modelling [25-28,112,131] }\end{array}$ & $\begin{array}{l}\text { 3D CFD - Solving the buoyancy-driven convection } \\
\text { flow in detail; visualizing thermal leakage. } \\
\text { 1D thermal modelling - Fast-running } \\
\text { Coupled 1D-3D - informative \& cost effective }\end{array}$ & $\begin{array}{l}\text { 3D CFD / Coupled - computing resources demanding } \\
\text { Solely 1D - error in predict heat transfer coefficients \& } \\
\text { cooldown trajectory can be misleading }\end{array}$ \\
\hline
\end{tabular}




\section{Cabin thermal model}

The vehicle cabin is the main plant for the Heating, Ventilation and Air Conditioning (HVAC) system. It should be able to simulate the dynamic change of the cabin heat load. A simplified 1D vehicle cabin generally is modelled as a lumped mass single moist air volume. The heat load on the cabin accounts for solar load acting on the cabin exterior surfaces (windows, roof, doors, etc.), metabolic loading from passengers, ambient conditions (air temperature, altitude and humidity) and the vehicle's drive cycle. The heat balance is calculated via radiation, convection and conduction based on which the averaged cabin air temperature distribution is simulated. A generic representation of a cabin lumped mass structure is illustrated in Figure 4.

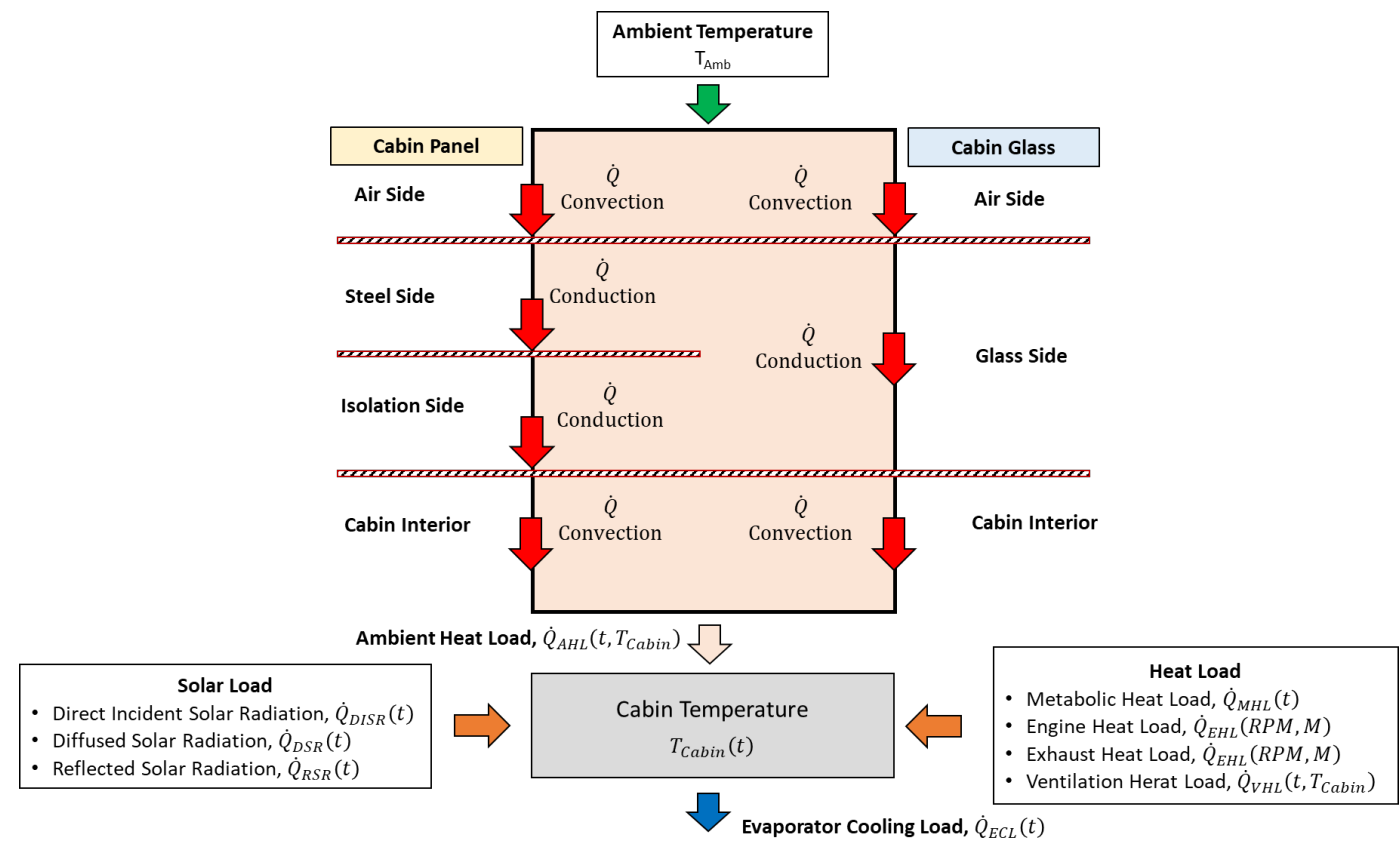

Figure 4. Generic Cabin Element Subsystem Layout.

\section{Link with the vehicle heating ventilation and air-conditioning system}

The main purpose of an automotive HVAC system is to regulate the temperature, airflow speed, humidity and cleanliness of the air within a vehicle cabin. The HVAC system must be able to create and maintain comfortable conditions for the passengers in the cabin. The vehicle HVAC system consumes significant amount of energy. At present the overall consumption of fuel relevant to passenger vehicles HVAC systems is between 10 to $15 \%$ [118]. As a result, the rise of the fossil fuels prices and stricter global regulations on vehicle exhaust emissions reduction are driving forward performance optimisation on automotive 
HVAC systems. The accurate calculation of the cabin thermal load has a noteworthy influence on the performance of vehicle energy consumption prediction models, especially in extreme temperature environments. Cabin heating is also a significant issue for full and plug-in hybrid vehicles in particular due to electric only operation and the lack of waste heat from the combustion engine.

\section{Cabin thermal load}

Some of the first automotive AC compressors were driven directly by the engine via a mechanical connection such as a system of pulleys and clutches. Those early designs did not allow for compressor speed control. The AC system sizing was done via the peak cabin thermal load. The AC systems thermal loads were determined mainly by the reference data graph method, which is not a precise approach but can be applied as a rough approximation method [119]. Due to vehicle design standardisation, the cabin volume can be roughly determined by the vehicle type, passenger capacity and other design factors. Thus, experimental data related to different standardised vehicle types can be implemented to determine the thermal load in similar scenarios. This approach is easy to pick up, but the obtained results can be treated only as indicative data.

However, the cabin thermal load prediction should not be constrained only to peak value approximations. Transient and real-time conditions should also be considered, which will result in the development of flexible theoretical models closer to the real-life conditions.

The continuous improvement in the field of automotive energy efficiency and savings has led to the development of thermal insulation materials with enhanced properties and pronounced thermal inertia intensity. Thus, the steady-state heat transfer modelling approach fails to model the cabin thermal load with high accuracy.

There are variable unsteady methods that can be applied to model dynamic thermal (heating and cooling) loads. The methods can be separated into two major groups. The first one encompasses the approximate differential equations solution solving approach to obtain the thermal load approximation [120]. The second one covers the dynamic thermal load calculation techniques like the transfer function coefficient technique [121] and the response-factor technique [122]. 
Solmaz et al. [123] developed an hourly cooling load model of a passenger car based on Artificial Neural Network (ANN) concept. The authors designated seven neurons to act as input signals for the input layer of the model. The used inputs are day of the year, hour of the day, longitude, latitude, hourly mean ambient air temperature, hourly solar radiation. The model has a dynamic steady-state nature, the ambient temperature and the vehicle velocity are time dependant. The main drawback of the model is the simplifying assumptions related to the thermal inertia of the different cabin elements. Thus, the thermal conduction through the cabin elements is compromised.

A low fidelity and dynamic steady-state thermal model was created and tested by Marcos et al.[124]. The model was validated for three distinct scenarios: parked and unoccupied vehicle while outdoors, parked and unoccupied vehicle while indoors and running vehicle with a single person in the cabin (the driver). The dynamic steady modelling approach yielded better results and proved that the model can be used for cabin thermal load estimation. Torregrosa-Jaime et al. [125] built a transient lumped-mass thermal model of a passenger vehicle cabin via a steady-state heat transfer approach. The authors were able to calculate the mean temperature and the relative humidity in the passenger compartment. Pokorny et al. [126] made a cabin model which simulates for the energy balance between the cabin and the outdoor environment conditions. The model considers the effects of the thermal conduction, convection and radiation. The model results were validated against test data for Skoda Felicia Combi passenger vehicle under different ambient conditions and drive cycles. The results comparison showed that the model can correctly estimate the test mean air temperature.

Besides the consideration of the external thermal load, the cabin thermal performance is closely related to the refrigerant system, which will be further addressed in section 4 thermal-fluids modelling.

\section{Underhood heat-retention model}

Within the new and more realistic fuel economy test, named WLTP (Worldwide harmonized Light-duty vehicle Test Procedure), the testing vehicles are required to be placed under the natural soak condition at $14^{\circ} \mathrm{C}$ ambient environment for 9 hours cooldown, to reflect the real-world situation of vehicle under parking, in between the first and the subsequent WLTP drive tests at $23^{\circ} \mathrm{C}$ and $14^{\circ} \mathrm{C}$ ambient temperature respectively [127]. 
Engine or vehicle thermal encapsulations will help keep the heat retained within the under-hood region and keep the fluid temperatures of the engine coolant and of the oil in the engine and transmission components at a higher level throughout the vehicle soak stage[128]. The heat retention from the soak is beneficial to subsequent cold start WLTP drive-cycle tests due to the reduced friction loss with increased oil temperatures, therefore provides benefits on both $\mathrm{CO}_{2}$ emissions and fuel economy. The elevated coolant temperature, on the other hand, helps the engine warm up to its operational conditions quicker, reducing cold-start fuel consumption. This section reviews the software capability and the state-of-the-art CAE methods of the heat retention modelling of the vehicle underhood region during the thermal soak. The importance of the development of the CAE methods for the heat retention analysis lies in that it enables the thermal encapsulation design being embedded into the early vehicle design stage for improving fuel consumption and reducing $\mathrm{CO}_{2}$ emissions in a timely and robust manner, aiding the development of modern low-carbon vehicles.

However, there are several challenges associated with modelling the heat transfer process of the vehicle under-hood. (1) Firstly, it is a transient process consisted with buoyance-driven convection, thermal radiation and heat conduction. High-fidelity computational fluid dynamics simulation is often needed to calculate the air flow and the associated convective heat transfer around the engine bay when vehicle undergoes the soak stage [24-26]. The flow solver is then combined with a thermal solver $[25,26]$ to calculate the thermal solutions with account of convection, conduction and/or radiation effects. The thermal distribution of the engine bay components interacts with the air flow, determining the accurate prediction of the fluids and metal temperature cool-down trajectories. (2) Secondly, the efficient design of the thermal encapsulation requires that the CAE method to take account of the complexity of the under-hood components geometries and is able to accurately model the buoyancy-driven transient heat transfer process as well as the thermal radiation and conduction process. This is often found challenging with the conventional CFD methods. (3) Finally, the trade-off between the computing cost and the prediction accuracies of the key fluids and components also become one of the considerations of the CAE modelling for the under-hood thermal modelling under the soak stage. 
One of the main factors and challenges to take account of when modelling the heat transfer process of the vehicle under-hood region during the static soak conditions is the thermally induced natural convective heat transfer modelling driven by buoyance. It usually requires a CFD flow solver to resolve the flow dynamics adjacent to the engine solids' surfaces and the convective heat transfer coefficients at the metal - air interfaces [26]. A similar heat transfer phenomenon driven by the buoyancy effect also occurs for the oil inside the engine oil sump during the vehicle cool-down period. Numerical simulation on the temperature stratification, indicated a strong spatial variation of the oil temperature inside the sump [112], suggesting that the usage of reduced-order simulation tools for the thermal cool-down prediction could be invalid, nevertheless that the non-turbulent flow regime in the oil sump allows a cost-effective computational modelling method to be carried out to analyse the free convection laminar flow.

There are in general two approaches for solving the buoyancy-driven convection flow. One is a steady 3D CFD method based on the solution of steady-state Navier-Stokes equations for continuity, conservation of momentum and energy [112], in which the heat radiation flux on the buoyancy-driven flow is taken account of using the surface-to-surface (S2S) radiation model. The alternative approach is an unsteady full-scale 3D CFD method using a particle-based Lattice-Boltzmann Method (LBM)[129]. The LBM approach is an inherently transient flow solver, which models fluid at a fundamental kinetic level using discrete Boltzmann equations governing the dynamics of particle distribution functions. It tracks the motions of macromolecules through space and time to simulate flows of gases and liquids. The aerodynamic flow field resolved by the CFD, which includes the near wall fluids properties such as air temperatures, mass flow rates and HTCs calculated from the CFD, were usually subsequently seeded into a separate heat transfer model, such as a 1D thermal engine model as boundary conditions to obtain the transient thermal cooldown behaviours of the engine solids and internal fluids.

To accurately predict the internal fluids' transient thermal cool-down behaviour during the soak conditions of 9 hours, flow - thermal coupled modelling approaches were applied by several studies $[25,26,112]$ featuring a detailed 3D CFD flow simulation to solve the natural convection flow and a relative fast running thermal solver to take account of the combined heat transfer process including thermal radiation and conduction effects as well 
as the convection effect. The flow and thermal solvers exchange data frequently at regular time intervals to obtain transient thermal solutions for engine-bay solids and the internal liquids (i.e. coolant, engine oil and transmission oil). The computing costs of coupled 3D transient flow - thermal simulations are usually found to be expensive $[25,26]$. It was reported of around 5000 CPU-hrs and 20,000 CPU-hrs for coupled simulations of 5 min's and 30 min's soak (physical time), respectively [26]. To overcome the computing resource restriction, a standalone fast running thermal model of the vehicle under-hood was used [26] following the high-fidelity coupled models to finish the simulation of the entire soak period. A simulation cost of 24 CPU-hrs was used for the 9 hours standalone thermal cooldown simulation. This demonstrated a coupled - standalone software integration for simulating buoyancy-driven heat transfer in a vehicle under-hood region during thermal soak with satisfied accuracy and efficient computing time.

A different coupled approach numerically for the buoyancy-driven flow and the heat retention in the under-hood region of the full-geometry passenger car was investigated by Minovski, et al. [112]. It featured a combining 3D steady-state CFD simulation in STARCCM+ with 1D thermal modelling in GT-SUITE. The 3D CFD was initialised with the temperatures of engine solids calculated at the end of the 1st WLTP cycle by the 1D engine thermal model in GT-SUITE. Heat transfer coefficients computed by the steady 3D CFD simulation of buoyancy-driven flow were fed into the 1D thermal representation of heat conduction in the engine solids. Next, a 1D engine thermal simulation was started for 20 second physical time, during which the heat transfer coefficient due to natural convection and radiation were taken as constants. Following the transient heat transfer 1D modelling, the temperature of solids were updated and re-mapped onto the 3D steady flow models to calculate the buoyancy flow. Radiation effects were taken account in the CFD model as well. In this study an overall computing cost of 24,000 CPU-hrs was required for a $16 \mathrm{hrs}$ simulated drive cycle.

\section{Benefits for $\mathrm{CO}_{2}$ emissions and fuel economy}

One major consideration for under-hood heat retention analysis and encapsulation designs is the potential benefits on engine friction loss reduction at the engine cold start, on $\mathrm{CO}_{2}$ emissions reduction and on fuel saving. Recent studies (experimental [130] and CAE [131]) have evaluated encapsulation designs and found around $6-10{ }^{\circ} \mathrm{C}$ temperature 
increases at the end of the 9 hours soak of the engine coolant and oils from the vehicle mounted encapsulation concept design. A $3 \mathrm{~g} \mathrm{CO}_{2} / \mathrm{km}$ benefit was noted with the concept design [130] for the $14^{\circ} \mathrm{C}$ ATCT WLTP cycle. Researchers have also linked the encapsulation heat retention analysis to 1D longitudinal vehicle dynamic model and 1D mapped engine performance model to predict the consequent fuel consumptions and $\mathrm{CO}_{2}$ emissions during a WLTP drive-cycle [112]. The vehicle simulation was implemented in GT-SUITE. At ambient temperature of $5^{\circ} \mathrm{C}$, a $2.5 \%$ fuel savings was found for the encapsulation with high degree (97\%) of coverage at engine-starts occurring $2 \mathrm{hrs}$ after key-off. Although improvement in the heat transfer prediction in the coolant jacket at low flow rates was pointed out of the 1D thermal engine model, which was suggested lead some discrepancy between the simulation results and the test data of the coolant and oil temperatures at the beginning $(0-20 \mathrm{~min})$ of the vehicle soak. This added uncertainty to the prediction of the fuel consumption saving for the second WLTP drive cycle. Further improvement and investigation are required to be able to accurately obtain the understanding of encapsulation heat retention benefits to the $\mathrm{CO}_{2}$ emissions and fuel economy.

\section{Thermal Fluids Modelling}

Thermal-fluids models simulate coolant and oil fluid behaviour and refrigerant loops for performance evaluations during vehicle warm-up, and simultaneous heating or pull-down of the cabin temperature. Figure 5 shows a diagram on an overall vehicle model indicating the thermal-fluids (blue and red arrows) flow connections to the vehicle powertrain and to the vehicle body (cabin and under-hood) via the high-temperature (HT) coolant circuit, the low-temperature (LT) coolant circuit, refrigerant / AC subsystem. 


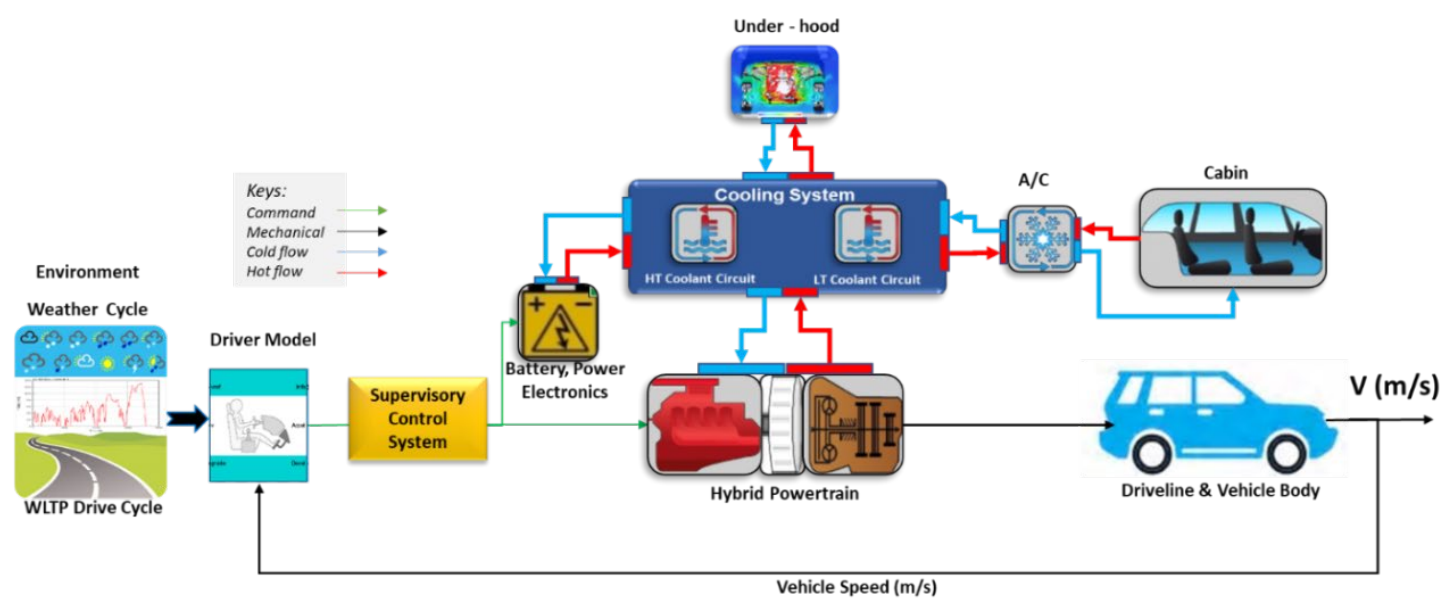

Figure 5. Thermal-fluids flow connections in the overall vehicle model

A wide variety of computational software and tools allow for the development of simulation models of different fidelities according to the needs and the stage of the development process. The virtual models are used for system-level design and optimisation, as well as for component-level design and sizing. The most common tools used for virtual model development are the 1D and the 3D CFD approaches. Although less computational demanding compared to the 3D CFD approach, the main drawback of the 1D modelling is the considerable number of assumptions and simplifications that need to be made. On the other hand, the 3D CFD [170, 171] modelling accounts for complex flow structures and the interaction of detailed pressure, temperature and velocity fields. The 1D modelling can be set up to run in real-time, or even faster than real-time, whereas in the case of 3D CFD, the models tend to run many times slower than real-time.

With co-simulation in mind, this review focuses on the 1D CFD lumped mass modelling approach of passenger cars' coolant circuits for vehicle warm-up, heating, hot soak and pull-down conditions, refrigerant loops, and HVAC system, which are essential to the performance evaluation of a vehicle thermal fluid system in the real world.

The overall 1D CFD simulation analysis allows for the evaluation of the performance of the fluid systems and enables the optimisation of individual components and the overall system during the vehicle design stage. The development of a $1 \mathrm{D}$ model can lead to reductions in the vehicle design procedure and costs. Some of key capabilities that are desirable in a 1D fluid model including the simulation of (1) the refrigerant loop identifying the refrigerant temperature and pressures at various locations, (2) the coolant circuits including engine and transmission warm up response, (3) air temperatures at the 
evaporators outlet, (4) the cabin compartment temperature distribution during warm-up, heating, and the steady-state, as well as the evaluation of the HVAC system power consumption under various drive cycles.

\section{High Temperature Coolant Circuit (powertrain cooling)}

The high-temperature coolant circuit is responsible for rejecting the thermal losses from conventional powertrain components such as the engine and transmission which typically operate in the range of $90-110^{\circ} \mathrm{C}$. Since the early 20 th century, the overall system design has changed relatively little, consisting of the components to be cooled, radiators and fans to pull air through the radiators. In the early 2000s, the introduction of electric fans and pumps [132] (rather than those mechanically driven by the engine) attracted research interest due to their ability to reduce fuel consumption and emissions by reduction of their output power [133] during conditions when limited air or coolant flow rates are required to meet cooling demand, for example switching off the radiator fan at high speed [134].

More recently, further gains have been made using complex control algorithms [135] to control electronic thermostatic valves (eValves) [136], auxiliary pumps, and radiator vanes to restrict cooling and to actively move heat between various components. In particular, this has realised a reduction in the engine and transmission warm-up time, reducing fuel consumption and emissions $[137,138]$ even further as discussed in Section 3.

\section{Low Temperature Coolant Circuit (power electronics, motors, batteries' cooling)}

Power electronics and electric motors tend to operate most efficiently at lower temperatures than combustion engines at approximately $50-70^{\circ} \mathrm{C}$ [139], and batteries tend to require even lower temperatures around $20-40^{\circ} \mathrm{C}$ [140]. As such, many hybrid vehicles tend to operate with either two or even three independent cooling circuits. Low temperature fluid circuits, operating around $60^{\circ} \mathrm{C}$, tend to require larger radiators than high temperature circuits due to the smaller temperature differential between the coolant and ambient conditions. However, brushless DC motors and the associated power electronics are highly efficient and therefore their overall cooling requirements are much smaller than a similarly sized combustion engine and in fact can often be air-cooled [141]. 
Additionally, in extreme conditions the motor peak power output can easily be reduced to manage the temperature, albeit with a corresponding loss of performance.

Battery cooling circuits, operating around $30^{\circ} \mathrm{C}$, will often require refrigerant based cooling so that the battery temperature can be reduced below ambient conditions (which may reach up to around $50^{\circ} \mathrm{C}$ in extremely hot climates). As such, battery cooling circuits are often integrated with the cabin air conditioning (AC) refrigerant circuit [53]. However, cooling of the batteries is not the end of the story. In cold climates, the high-power batteries may require pre-heating [142] before they can output a useful current, this is due to reduced chemical kinetics. Based on experimental studies, Zhang et al. [143] report that the usable capacity of a Li-Ion chemistry battery can drop to less than $80 \%$ at $0^{\circ} \mathrm{C}$ compared with the nominal capacity under room temperature $(25 \mathrm{deg} C)$ and only $65 \%$ of the battery nominal capacity is usable below $-10^{\circ} \mathrm{C}$. Tourani et al. [144] used correlated electrochemical models to show only $5 \%$ of the nominal capacity is accessible at $-33^{\circ} \mathrm{C}$. Typically for hybrid vehicles, this requires limiting the use of the batteries until they have been heated by waste heat from the combustion engine, but battery electric vehicles may require some source of external heat input such as resistive or positive temperature coefficient (PTC) heaters. The use of which may reduce the overall range [14].

In addition to the consideration of optimum performance and operating temperatures of batteries, the ageing of the batteries is another important aspect, which is closely related to the temperature, requiring for the optimum thermal management. The ageing of the batteries, particularly the degradation of the Solid Electrolyte Interface (SEI) is significantly affected by elevated temperatures. The SEI simultaneously prevents corrosion of the charged electrode and limits reduction of the electrolyte, but over the lifetime of the battery, it will gradually penetrate into the pores of the electrodes and separator causing an increase in internal resistance [145]. The kinetics of this reaction are accelerated by high temperature and excessive heat can even result in exothermic side reactions causing catastrophic failure of the cell ("thermal runaway"). Even without thermal runaway, degradation of the SEI is considered to be the most significant cause of capacity loss in modern electric vehicles $[49,146]$. Similarly, the chemical kinetics of other ageing methods, such as solvent co-intercalation (due to over-charging [146]), current collector corrosion (due to deep-discharge [146]) and structural changes to the active material, are increased 
with elevated temperatures. Conversely, low temperatures can be an issue too. In particular, lithium metal plating occurs when lithium metal directly reacts with the electrolyte, resulting in resulting in an associated mass reduction of the electrolyte. Lithium metal plating is caused by inhomogeneous distribution of current and potential often as a result of operating the battery at high load in a low temperature environment [147]. In summary, Vetter et al. [147] suggest that the internal battery temperature should be maintained below $60^{\circ} \mathrm{C}$ in order to limit SEI decay and should never exceed $80^{\circ} \mathrm{C}$ in order to prevent thermal runaway. Zhang et al. [145] demonstrate significant increases in capacity loss and internal resistance when cycling Lithium Iron Phosphate batteries at $0^{\circ} \mathrm{C}$ and $-10^{\circ} \mathrm{C}\left(20 \%\right.$ and $25 \%$ respectively after 600 cycles) when compared to operation at $45^{\circ} \mathrm{C}$ and $25^{\circ} \mathrm{C}$ (around $15 \%$ ).

\section{Refrigerant subsystem}

A generic representation of a refrigerant subsystem is shown in Figure 6. All refrigeration components must be calibrated with their respected geometry and performance data. The compressor and thermal expansion valves models are performance based. The heat exchanger models are geometry and performance based. The modelled refrigeration network represents a cooling subsystem. The single cooling subsystem includes one evaporator situated in the front section of the base line vehicle. The vehicle speed is defined in accordance with the desired drive cycle. The inputs to the model are compressor speed and displacement, condenser inlet conditions (air flow rate, temperature and relative humidity), evaporator inlet conditions (air flow rate, temperature and relative humidity). 


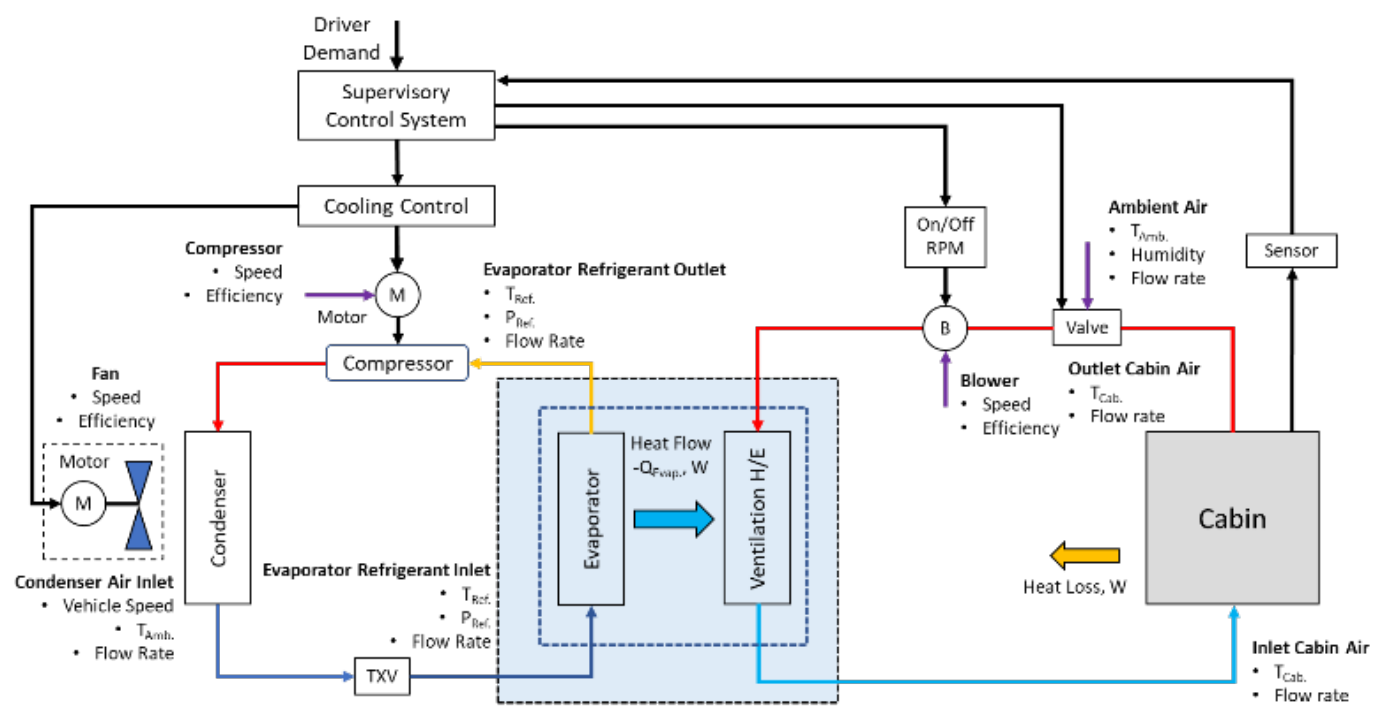

Figure 6. Cooling subsystem components layout

\section{Overview of the numerical approaches}

As discussed previously, utilising CFD can deliver theoretically and numerically accurate solutions, however, the main drawback of which is the long computational time which is not able to meet the required fast response in vehicle thermal load fluctuations. In contrast reduced order models are favourable towards vehicle-level engineering calculations and performance prediction of dynamic AC thermal loads due to their fast response. One of the earliest CAE studies of thermal-fluids system is done by Davis et al. in 1972 [21]. The authors have developed a simulation package for air conditioning system analysis based on analytical procedures. The theoretical model is validated against test data. Limperich et al. [22] developed a vehicle refrigeration cycle model via the application of Dymola and Modelica software. The researchers have conducted an evaporator validation at the system's component level. Several compressors with different parameters were tested via the New European Drive Cycle (NEDC) and their refrigeration cycles theoretical results were compared.

Austin and Botte [23] developed an integrated approach to combine air conditioning and cooling circuits. The vehicle cabin thermal load evaluation has evolved from a steadystate peak value calculation approach to a real-time fully dynamic approach. The steadystate heat transfer estimation approach offers simple to calculate algorithms, but the resulting accuracy is compromised. Li et al. [148] developed a steady-state thermal AC system model. The model considers the effect of the passenger cabin, ambient conditions, 
in-cabin conditions, vehicle speed (drive cycle), air volume, solar load and number of passengers. Kiss et al. [149] developed a MATLAB/Simulink transient vehicle AC model comprised of a cooling network and cabin subsystems. The refrigeration network uses a finite volume approach for the governing equations formulation. The refrigerant network layout is structured by $1 \mathrm{D}$ pipe blocks linked via $0 \mathrm{D}$ volume blocks. The cabin subsystem has been modelled as a simple lumped air/water vapour volume with included interior thermal mass and cabin structure. The researchers reported that the model is capable of handle the fast transients that occur in an automotive AC system. Comparison of the numerical data with steady state test data shows a good fit between them, with average refrigerant mass flow error of $3.1 \%$. The model can be integrated into vehicle models for the purpose of overall vehicle energy analysis and optimisation.

A Dymola-based electric vehicle thermal management model consisting of multiple submodels like battery, cabin, heat pump and heat pump control unit models was created by Jeffs et al.[150]. The model allows for the automated connection and disconnection of various thermal management systems, control heat flows according to ambient conditions, demand and operational regimes of the components, thus explore different control strategies and their effect over the vehicle performance especially in cold climates. The authors had tested the model over several test cases consisting of multiple scenarios. The simulation results have not been compared to test data.

Future work and challenges with thermal-fluids and the associated HVAC modelling lie in the development and the validation of combined high fidelity-1D HVAC system model, which features a modular structure for robust alterations and adjustments to different vehicle architectures (conventional, EV, HEV). Research the application of the neural network approach for Fast Running Model (FRM) conversion and enable the 1D HVAC model to be co-simulated with vehicle models would also be desirable.

Key modelling techniques of the thermos-fluid simulation are summarized in Table 3, as well as their performances. 
Table 3 - Summary of Thermo-Fluid Simulation Techniques

\begin{tabular}{|c|c|c|c|}
\hline Technique & Examples & Advantages & Disadvantages \\
\hline Lumped Mass & $\begin{array}{l}{[21-23,28,} \\
106,123- \\
126,148, \\
150]\end{array}$ & $\begin{array}{l}\text { Straight-forward } \\
\text { implementation, consideration } \\
\text { of a wide range of components, } \\
\text { suitable for optimisation tasks }\end{array}$ & $\begin{array}{l}\text { Low fidelity, minimal } \\
\text { consideration of control } \\
\text { strategy, no thermal } \\
\text { distribution across components }\end{array}$ \\
\hline 1D CFD & $\begin{array}{l}{[22,23,28,} \\
120,122, \\
124-126 \\
148,150]\end{array}$ & $\begin{array}{l}\text { Higher fidelity, relatively fast } \\
\text { simulation, can still be used for } \\
\text { optimisation (within reason), } \\
\text { detailed consideration of control } \\
\text { strategy }\end{array}$ & $\begin{array}{l}\text { Slower than above, significant } \\
\text { correlation effort required, } \\
\text { usually based on empirical } \\
\text { data, minimal consideration of } \\
\text { interaction with dynamic } \\
\text { aspects of powertrain }\end{array}$ \\
\hline 3D CFD & $\begin{array}{l}{[26,27,} \\
170,171]\end{array}$ & $\begin{array}{l}\text { Highest fidelity, consideration } \\
\text { of localised 'hot-spots', complex } \\
\text { flow structures interactions, } \\
\text { advanced fluid thermal } \\
\text { behaviour prediction }\end{array}$ & $\begin{array}{l}\text { Slow to simulation, not } \\
\text { possible to perform } \\
\text { optimisation, often considering } \\
\text { only a small number of specific } \\
\text { test cases }\end{array}$ \\
\hline Co-Simulation & [28] & $\begin{array}{l}\text { Concurrent high-fidelity } \\
\text { consideration of thermo-fluids } \\
\text { and powertrain performance }\end{array}$ & $\begin{array}{l}\text { High development effort, slow } \\
\text { simulation time }\end{array}$ \\
\hline
\end{tabular}

\section{Model architecture and Co-Simulation Methodology}

A numerical model is fit for purpose when its level of detail adequately meets certain requirements [2]. Very detailed models can be developed if subsystems of different domains and disciplines, each developed in area-specific software, are integrated into a single global model using co-simulation and/or model integration techniques $[1,4,8]$. Most modern simulation environments support the connection to other environments [4] via one or more methods, thus combining the strengths of the associated environments $[9,10]$. The integrated models incorporate the full dynamic behaviour of the system. This allows the engineers to implement a truly holistic approach in the early-stage design and concept validation of subsystems and thus is highly suited to thermal modelling of drive-cycles. In terms of the controller development, engineers can front-load control software 
development and testing using real-time co-simulation[151], in which case models are exported to, and simulated on, a real-time computer.

\section{Integration Interfaces}

In terms of model interchangeability, model integration interfaces are divided into two main groups:

a. Proprietary interfaces are specific to a certain combination of global/local environments. For example, most automotive simulation environments feature proprietary interfaces that connect specifically to Simulink. Usually, such interfaces connect the two platforms via a virtual server and each model is simulated in its original platform. During simulation, the two platforms exchange data via the virtual server $[4,152,153]$.

b. Tool agnostic interfaces are supported by a wide array of commercial software packages and therefore they promote global model interchangeability. The Functional Mock-up Interface (FMI) is currently the most widely supported model integration specification and Functional Mock-up Units (FMUs) with distinct characteristics can be tailored to the user's needs. In addition to the FMI, the MATLAB S-function can be considered a tool agnostic interface when real time computer simulation is considered.

Co-simulation interfaces can also be classified with respect to their numerical solver configuration as shown in Figure 7. The two main categories are summarised as follows:

a. Model Exchange (ME) enables the user to export a model from one platform and simulate it in another platform using the host platform's numerical solver. The simulation in this case takes place on a single solver under a single simulation time step (barring any advanced solver configuration in the host environment).

b. Co-Simulation (CS) involves the simulation of each integrated sub-model by its own dedicated, domain-specific solver [151]. A global solver manages the simulation order and model communication. This general family of model integration methods allows for each connected (local) sub-model to run under a different solver and simulation time step that is most suitable in handling the stiffness of the individual sub-model. 


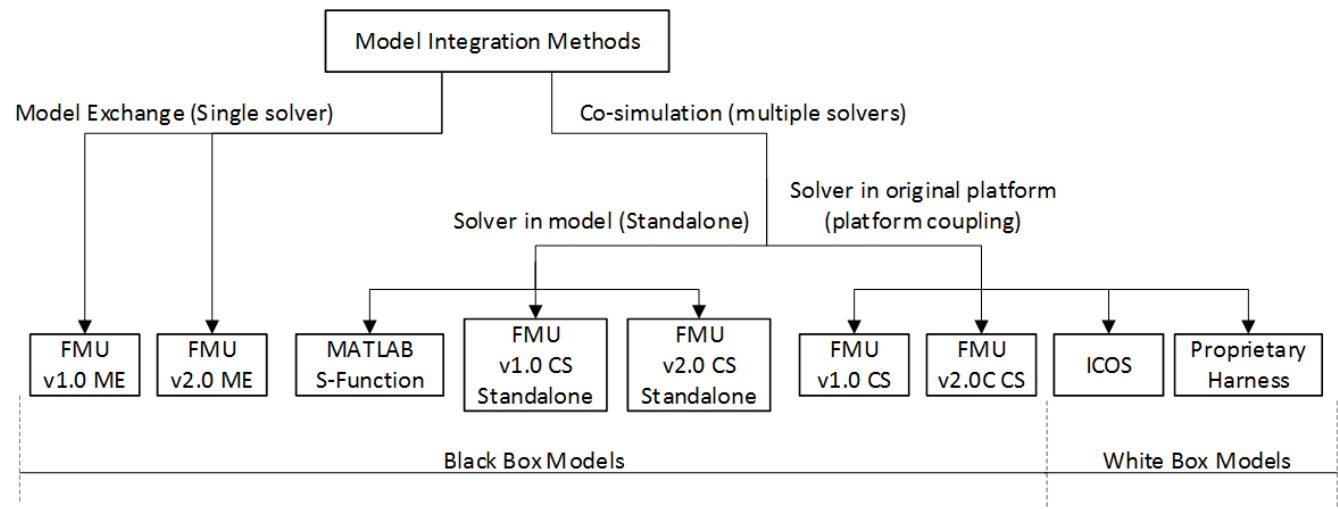

Figure 7. Tree diagram of commonly encountered model integration methods in the automotive sector.

The numerical solver configuration of each model integration method is shown in Figure8. FMI for ME models (Figure 8A) are simulated on the solver of the host environment. If the host solver is suitable to the imported model, this method can be very accurate and fast running. In addition, the model file size is smaller (due to the lack of integrated solver code) and the model can run without the need for an installation of the original platform. The potential drawback of this method is the fact that different domains are often better simulated under different solvers and time steps. All other integration methods involve a multi-solver simulation. The multi-solver model integration methods are subdivided into two main categories. In the first category, the numerical solver of the original platform is embedded within the exported model (FMU CS Standalone or Sfunction) and the local simulation takes place within the host platform using the original solver. This method tends to result to a faster co-simulation when compared to any platform coupling method. In addition, co-simulation is possible without the need for an installation of the original platform. The main disadvantage of this method, in particular for the FMU CS standalone is the large file size that in some cases may complicate file storage and sharing. In the second category, the associated platforms are coupled via a virtual server and each model is simulated on its original platform. The main advantage of this method is that in the cases of the proprietary interface and the ICOS (Linux based network operating system) interface, the models are "white-box" (i.e., open and accessible) and this allows for a fast development time as no recompilation of the local model is needed. Another advantage that characterizes all platform coupling interfaces is the small 
file size. The disadvantages of platform coupling options are the relatively slow simulation speed and the need for the presence of installations for all the associated software.
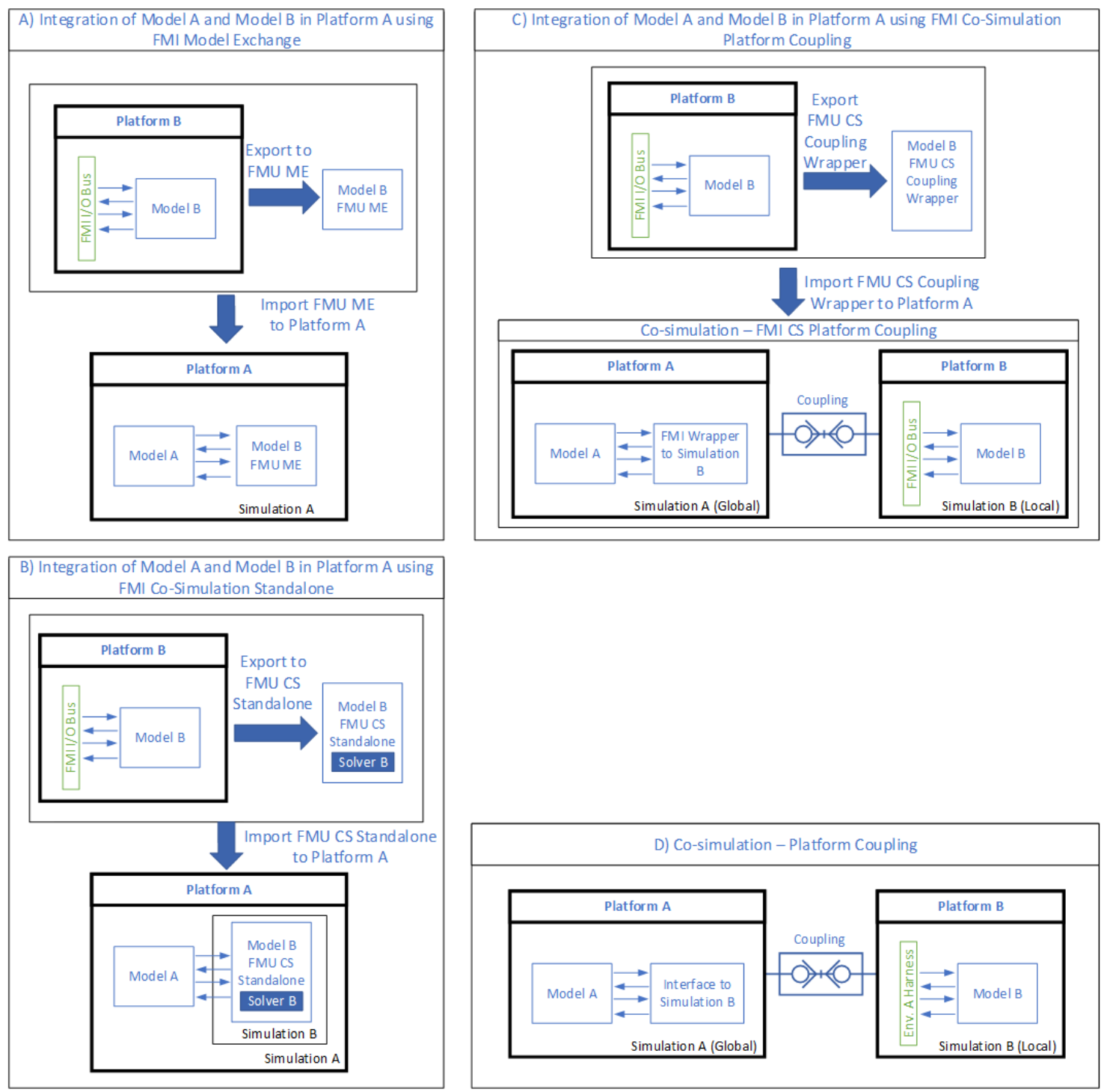

Figure 8. Diagrams on solver configuration for different integration methods.

All interfaces discussed above have a good to excellent support from engineering software companies. The FMI standard is the most supported integration interface with respect to both import and export capability while also being supported by many real-time environments. FMI ME can be particularly useful when a model is to be shared in "black box" form and the model is compatible to the solver used in the host model. FMI CS standalone is suitable when simulation speed must be high (e.g. optimisation), and the model must be shared in a black box form with a user that may not have a full installation 
of the software but has a solver license of the original software. MATLAB S-function is highly popular in applications in which high simulation speed of a black box model running in MATLAB/Simulink environment is the main priority. Export to S-function is supported by a large number of simulation environments. The S-function can be directly imported to MATLAB/Simulink target and to a large number of real-time computers. When there is a need to make fast changes to the associated models and observe the response, such as during model development, proprietary platform coupling interfaces are the most suitable solution.

Finally, it should be noted that most software packages make it very simple to transfer from one type of interface to another. Therefore, development can take place using platform coupling and then the interface switched to model exchange or standalone cosimulation for faster performance in optimisation tasks once the model development has matured.

\section{Co-simulation}

The following constitute to the increasing popularity of co-simulation across several disciplines involved in the development cycle of vehicles and there are numerous published studies from the automotive sector proving the usefulness of the concept of model integration. Le Marrec et al.[5] carried out functional validation of the initial engine control unit (ECU) specification. For this purpose, they setup a co-simulation using vehicle communication interface (VCI) to integrate software, hardware, and mechanical components modelled in C language, VHDL, and MATLAB respectively into a MATLAB global simulation. Li et al. [154] co-simulated a CarSim vehicle dynamics model with a Simulink anti-lock braking system (ABS) controller capable of targeting the optimal tyre slip ratio for a given tyre pressure. The simulation results of the novel ABS controller were compared to the results of a baseline simulation with a conventional ABS controller. Xie et al. [155] setup a co-simulation between an AMESim vehicle model equipped with a dual state continuously variable transmission (CVT), and a MATLAB/ Simulink transmission control unit and torque converter controller model. The co-model was validated on a typical drive cycle for passenger cars. Reyneri et al. [6] developed a test bench for fuel injection systems. The test bench comprised of a co-simulation between the hardware model running in FPGA, the software model running on a PC, and the physical 
electromechanical parts. The electromechanical components were modelled using a trained neural network and used with the software and hardware models to co-design injection control. Maharun et al.[152] built a plug-in hybrid electric vehicle (PHEV) comodel by means of integrating an ADAMS/Car vehicle model with a Simulink model representing the Energy Management System (EMS), the Fuzzy Vehicle Dynamics Controller (VDC), and the electrical components. The co-simulation was used to evaluate the EMS and VDC in terms of the improvement in fuel consumption and vehicle handling characteristics respectively. Wu et al. [2] investigated the potential for shift quality and fuel efficiency improvement coordinated engine and gearbox control has for vehicles. Simulink served as the global simulation environment. The co-simulation involved a Simulink engine and shift controller model, a GT-Power engine model, and an AMESim torque converter - transmission - vehicle dynamics model. Mikelsons et al. [1] carried out a functional validation of the ECU with the use of a co-simulation between a CarMaker vehicle dynamics model, a GT-Suite powertrain model and the investigated ETAS EVE yaw rate controller model. Models were exported to FMU and co-simulated in AVL Model.CONNECT. Casoli et al. [7] designed an optimal fluid power circuit and engine combination and a control strategy for increased fuel economy of mobile machinery using a co-simulation of a Simulink ICE model and an AMESim fluid power circuit model. The AMESim model was exported to an S-function and then imported to Simulink. Li et al. [156] tested the performance of a Fuzzy ESP control strategy in terms of vehicle handling stability by co-simulating an ADAMS/CAR multibody dynamics vehicle model and a Simulink ESP controller model. Özener et al. [157] optimized the speed profile of city busses for a given route and for interstation route segments with respect to fuel consumption and emissions using a co-simulation of an IPG Truck Maker 3D articulated bus model \& road model connected to an AVL Cruise drive train model. Models were integrated via the use of a dedicated co-simulation interface. Eckert et al. [153] optimized gear shifting strategy with respect to fuel consumption and vehicle performance using a co-simulation between an ADAMS multibody dynamics vehicle model and a Simulink longitudinal dynamics model. Khan et al.[9] used a co-simulation between an ADAMS multibody dynamics 3D vehicle model and an LMS AMESim driveline model with a powertrain controller to predict vehicle Noise, Vibration, and Harshness. The models were 
integrated via exporting the ADAMS model to FMU and importing the FMU into the AMESim model. Karvonen et al. [158] studied the current and voltage harmonics induced on the DC bus of an electric drive by switching events using a co-simulation between an ANSYS Maxwell magnetic component model of the electric machine, and an ANSYS Simplorer model of all other components of the electric machine as well as the drive. Klein et al. [10] developed a model in loop (MiL) vehicle model co-simulation on dSpace VEOS. The co-simulation consisted of a vehicle dynamics model in dSpace VSM, a GT Power fastrunning engine model, an automatic double-clutch transmission model in Simulation $X$ (exported to FMU CS), a vehicle model in ASM Tool Suite, and a transmission control unit in Simulink. Following the validation of the concept on the MiL, the GT-Suite engine was replaced by a real engine on a dyno and an Engine in Loop test cell was commissioned with the purpose of studying the effects of varying engine parameters on a real engine. Fletcher et al. [25] developed a co-simulation of an engine test cell by integrating a GTDI Ricardo WAVE RT engine model within a Simulink StateFlow chart-based test cell controller and PCM model using the dedicated Simulink block, and used the co-simulation to develop an automated engine calibration validation tool. Zhang et al. [12] developed cosimulations of vehicle suspension durability rigs. The co-simulation comprised of an ADAMS mechanical components model, and a Simulink hydraulics and control elements model. The co-simulation was controlled using Remote Parameter Control Pro Software by opening a virtual server connection between ADAMS and Simulink.

The main characteristics of the model integration standards discussed above are presented in tabulated form in Table 4. 
Table 4 - Popular model integration standards and associated characteristics

\begin{tabular}{|c|c|c|c|c|c|c|}
\hline & \multicolumn{6}{|c|}{ Model Integration Interfaces } \\
\hline Criteria & $\begin{array}{l}\text { FMU } \\
\text { ME } \\
{[159-} \\
161]\end{array}$ & $\begin{array}{l}\text { MATLAB } \\
\text { S-function } \\
{[7,162-} \\
167]\end{array}$ & $\begin{array}{l}\text { FMU CS } \\
\text { Standalon } \\
\text { e } \\
{[9,159]}\end{array}$ & $\begin{array}{l}\text { FMU CS } \\
\text { Platform } \\
\text { Coupling } \\
{[8,9,53,159]}\end{array}$ & $\begin{array}{l}\text { ICOS } \\
{[168,169]}\end{array}$ & $\begin{array}{l}\text { Proprietary } \\
\text { Platform } \\
\text { Coupling } \\
\text { Harness } \\
{[2,10,152,154,1} \\
55]\end{array}$ \\
\hline $\begin{array}{l}\text { Support by } \\
\text { software }\end{array}$ & $\begin{array}{l}\text { Very } \\
\text { High }\end{array}$ & $\begin{array}{l}\text { Very } \\
\text { High }\end{array}$ & $\begin{array}{l}\text { Very } \\
\text { High }\end{array}$ & Very High & $\begin{array}{l}\text { High } \\
\text { (Virtual } \\
\text { Vehicle) }\end{array}$ & High \\
\hline $\begin{array}{l}\text { Simulation } \\
\text { Speed }\end{array}$ & $\begin{array}{l}\text { Very } \\
\text { High }\end{array}$ & $\begin{array}{l}\text { Very } \\
\text { High }\end{array}$ & $\begin{array}{l}\text { Very } \\
\text { High }\end{array}$ & $\begin{array}{l}\text { Ranges from } \\
\text { Slow to High }\end{array}$ & $\begin{array}{l}\text { Ranges } \\
\text { from Slow } \\
\text { to High }\end{array}$ & $\begin{array}{l}\text { Ranges from } \\
\text { Slow to High }\end{array}$ \\
\hline $\begin{array}{l}\text { Model } \\
\text { Configurability }\end{array}$ & Poor & Poor & Poor & Poor & Excellent & Excellent \\
\hline $\begin{array}{l}\text { Simplicity in } \\
\text { Procedure } \\
\text { Setup }\end{array}$ & Simple & Simple & Simple & Simple & $\begin{array}{l}\text { Very } \\
\text { Simple }\end{array}$ & Very Simple \\
\hline Multiple solvers & No & Yes & Yes & Yes & Yes & Yes \\
\hline $\begin{array}{l}\text { Weak coupling } \\
\text { capability }\end{array}$ & No & Yes & Yes & Yes & Yes & Yes \\
\hline $\begin{array}{l}\text { Installation of } \\
\text { original } \\
\text { platform }\end{array}$ & No & No & No & Yes & Yes & Yes \\
\hline Model Access & $\begin{array}{l}\text { Black } \\
\text { Box }\end{array}$ & Black Box & Black Box & Black Box & White Box & White Box \\
\hline Model file size & Small & Small & $\begin{array}{l}\text { Very } \\
\text { Large }\end{array}$ & Very Large & Small & Small \\
\hline
\end{tabular}

\section{Summary}

This paper reviews the state-of-the-art numerical approaches for the virtual holistic thermal and energy management of hybrid vehicles, including the overall model architecture, longitudinal vehicle powertrain, engine warm-up, heating ventilation and air-conditioning, thermo-fluids, cabin and under-hood heat retention models.

The overall system design by co-simulation modelling for thermal analysis and energy management is addressed to provide connections between subsystem models which 
captures, in sufficient detail, the interaction between mechanical, electrical, hydraulic and thermal domains. The development of a cost-effective holistic vehicle co-simulation platform is overviewed in terms of simulation time and running costs, as well as capability of calculating vehicle fuel consumption and emissions across a wide range of operating conditions.

The aim of the under-hood heat retention analysis is to predict the thermal cool-down behaviour of the engine bay compartments and the key fluids within. It provides a thermal analysis tool that enables the design of thermal encapsulations to be embedded into early stage of the vehicle design, which gives the potential of elevating fluids temperatures of engine coolant, engine oil and transmission oil to help reduce the friction loss associated with engine cold start. The heat retention model analysis and encapsulation optimisation thus lead to the benefits of $\mathrm{CO}_{2}$ emissions reduction and fuel economy.

The holistic vehicle model development will enable the thermal energy management for hybrid vehicles and push forwards low-carbon transport technologies in a time- and cost-efficient way, satisfying future legislative requirements. However, there are significant challenges required in order to make a holistic thermal vehicle model possible including the requirement for increased levels of communication between traditionally separate teams and a massive reduction in the computation intensity of various CFD and 1D flow models.

\section{Future work and challenges}

Future challenges in vehicle powertrain modelling revolve around two major step changes in the automotive industry as a whole. Firstly, changes in legislation have shifted the focus of powertrain development from steady state analysis at a few key engine operating points to a wide-ranging dynamic analysis (inclusive of human-machine interaction) which is much more representative of real-world driving. In effect, the onus to minimise real-world emissions has been shifted from government testing agencies to automotive OEMs by the removal of many of the loopholes surrounding historic legislation and the persistent possibility for comparison to real-world independent testing [28]. Secondly, the increased complexity and interconnectivity of modern powertrains has pushed automotive companies to consider a much more holistic view of the vehicle. It is no longer acceptable to design individual components in relative isolation, but instead the 
interaction between engine, motors, battery and auxiliary systems needs to be considered in much more detail and at an earlier stage in the production process [51].

At the management level, these changes are presenting logistic challenges due to the requirement for highly interdisciplinary working groups with representatives from many teams within the company. These groups require stronger technical communication pathways to be forged due to the increased levels of collaboration between teams which were previously only linked at a managerial level ("silos of engineering" [124]). Therefore, novel working processes are being developed, such as virtual teams [125], in order to cope with this new challenge.

On the technical level, the requirement for higher fidelity powertrain systems modelling is pushing the limits of computational efficiency. Previously simplified holistic models must incorporate much more detail and a wider range of components including the cabin climatic control [91], engine cooling as well as increasingly complex hybrid components such as batteries, motors, and power electronics. At the same time, they are still required to run significantly faster than real-time in order to perform parameter sweeps, design-of-experiment analysis, and optimisation techniques. Not only does the increased fidelity tend to result in increased simulation times, but it also increases development time and effort, which is itself exacerbated by the fact that no single hybrid powertrain architecture currently dominates. As a result, advanced modelling techniques such as acausal physics-based modelling [48,49], model reduction [87] and co-simulation $[51,105,113]$ are becoming increasingly important, if not necessary.

Key recommendations for further work are centred around the efficient use of cosimulation and acausal models in order to minimise development effort. Whereas, cosimulation is now commonly used, many of the examples shown here use it for a single purpose (e.g., design analysis or a co-optimisation task), and there are still very few demonstrations of working processes demonstrating acausal models or co-simulation component models designed for re-usability, which is one of the key potential benefits of these technologies. This is an area which is often overlooked by academia but has significant impact on hybrid vehicle development time and cost.

With regard to optimisation, co-simulation is not often the best choice due to its computational overhead. Instead, further work is required to develop predictive, fast 
running, and dynamic models of hybrid components, particularly batteries. This is an area in which model reduction techniques should play a significant part.

It is important to integrate the existing battery thermal management models to the vehicle ICE models and the vehicle body thermal model to optimise the energy and thermal distributions. To develop a CAE thermal analysis tool integrated in the vehicle design stage, which can accurately advise the optimum system design and the associated $\mathrm{CO}_{2}$ and fuel savings, a few key points are to be addressed for future investigations, such as (1) an integrated cabin thermal - heat retention - vehicle powertrain - battery thermal management model to obtain predictions on $\mathrm{CO}_{2}$ emissions and fuel consumptions; (2) the development of reduced order simulation methods, for instance using neutral networks or other machine learning methods, to obtain a fast running model in parallel to the highfidelity model; and (3) CAE aided analysis and guidance to the vehicle heat scheduling design in terms of $\mathrm{CO}_{2}$ emissions savings.

Supplementary Materials: none.

Acknowledgments: The authors would like to acknowledge the funding support from the Innovate UK and the Advanced Propulsion Centre (APC) for carrying out this work.

Conflicts of Interest: The authors declare no conflict of interest.

\section{References}

[1] L. Mikelsons, R. Samlaus, Towards Virtual Validation of ECU Software using FMI, Proc. 12th Int. Model. Conf. Prague, Czech Republic, May 15-17, 2017, 132 (2017) 307-311.

[2] T. Wu, K. Han, L. Pei, C. Zhao, Co-Simulation Study of Coordinated Engine Control Focusing on Tracked Vehicle Shift Quality, J. Autom. Control Eng., 2 (2014) 160-165.

[3] J. Fitzgerald, P.G. Larsen, K. Pierce, M. Verhoef, S. Wolff, Collaborative Modelling and Co-simulation in the Development of Dependable Embedded Systems, in: Springer, Berlin, Heidelberg, 2010: pp. 12-26.

[4] N. Pedersen, J. Madsen, M. Vejlgaard-Laursen, Co-Simulation of Distributed Engine Control System and Network Model using FMI \&amp; SCNSL, IFAC-PapersOnLine, 48 (2015) 261-266.

[5] P. Le Marrec, C.A. Valderrama, F. Hessel, A.A. Jerraya, M. Attia, O. Cayrol, Hardware, software and mechanical cosimulation for automotive applications, in: Proc. Int. Work. Rapid Syst. Prototyp., IEEE Comput. Soc, 1998: pp. 202-206.

[6] L.M. Reyneri, E. Bellei, E. Bussolino, L. Mari, F. Renga, Codesign and Cosimulation of Automotive Systems 
Based on Matlab / Simulink, in: Semin. Anu. Automática, Electrónica Ind. e Instrumentación, 2002.

[7] P. Casoli, A. Gambarotta, N. Pompini, L. Riccò, Development and Application of Co-simulation and "Controloriented" Modeling in the Improvement of Performance and Energy Saving of Mobile Machinery, Energy Procedia, 45 (2014) 849-858.

[8] S. Klein, R. Savelsberg, F. Xia, D. Guse, J. Andert, T. Blochwitz, C. Bellanger, S. Walter, S. Beringer, J. Jochheim, N. Amringer, Engine in the Loop: Closed Loop Test Bench Control with Real-Time Simulation, SAE Int. J. Commer. Veh., 10 (2017) 2017-01-0219.

[9] I.M. Khan, M. Datar, W. Sun, G. Festag, T. Bin Juang, N. Remisoski, Multibody Dynamics Cosimulation for Vehicle NVH Response Predictions, SAE Int. J. Veh. Dyn. Stability, NVH, 1 (2017) 2017-01-1054.

[10] B. Zhang, Q. Cai, Y. Lu, J. Wang, L. Wang, W. Chen, L. Yao, Y. Gu, T. Gu, S.S. You, Component Tests Based on Vehicle Modeling and Virtual Testing, in: SAE Tech. Pap., 2017.

[11] J. Kim, J. Oh, H. Lee, Review on battery thermal management system for electric vehicles, Appl. Therm. Eng., (2019) 192-212.

[12] W. Wu, S. Wang, W. Wu, K. Chen, S. Hong, Y. Lai, A critical review of battery thermal performance and liquid based battery thermal management, Energy Convers. Manag., (2019) 262-281.

[13] M. Al-Zareer, I. Dincer, M.A. Rosen, A review of novel thermal management systems for batteries, Int. J. Energy Res., 42 (2018) 3182-3205.

[14] Q. Wang, B. Jiang, B. Li, Y. Yan, A critical review of thermal management models and solutions of lithium-ion batteries for the development of pure electric vehicles, Renew. Sustain. Energy Rev., 64 (2016) 106-128.

[15] H. Liu, Z. Wei, W. He, J. Zhao, Thermal issues about Li-ion batteries and recent progress in battery thermal management systems: A review, Energy Convers. Manag., 150 (2017) 304-330.

[16] S. Arora, Selection of thermal management system for modular battery packs of electric vehicles: A review of existing and emerging technologies, J. Power Sources, 400 (2018) 621-640.

[17] L. Song, J.W. Evans, Electrochemical-Thermal Model of Lithium Polymer Batteries, J. Electrochem. Soc., 147 (2000) 2086.

[18] L.H. Saw, Y. Ye, A.A.O. Tay, W.T. Chong, S.H. Kuan, M.C. Yew, Computational fluid dynamic and thermal analysis of Lithium-ion battery pack with air cooling, Appl. Energy, 177 (2016) 783-792.

[19] R.D. Jilte, R. Kumar, Numerical investigation on cooling performance of Li-ion battery thermal management system at high galvanostatic discharge, Eng. Sci. Technol. an Int. J., 21 (2018) 957-969.

[20] W. Nessim, F. Zhang, Powertrain Warm-Up Improvement Using Thermal Management Systems, Int. J. Sci. Technol. Res., 1 (2012) 151-155.

[21] G.L. Davis, F. Chianese, T.C. Scott, Computer simulation of automotive air conditioning - Components, system, and vehicle, in: SAE Tech. Pap. (SAE International, 1972). doi:10.4271/720077.

[22] D. Limperich, M. Braun, K. Prölß, System simulation of automotive refrigeration cycles, Proc. Fourth Int. Model. Conf., (2005) 193-199.

[23] K. Austin, V. Botte, An integrated air conditioning (AC) circuit and cooling circuit simulation model, in: SAE Tech. Pap., 2001. doi:10.4271/720077

[24] K.-H. Chen, J. Johnson, P. Merati, C. Davis, Numerical Investigation of Buoyancy-Driven Flow in a Simplified Underhood with Open Enclosure, SAE Int. J. Passeng. Cars - Mech. Syst., 6 (2013) 805-816.

[25] B.B. Minovski, L. Lofdahl, P. Gullberg, A 1D Method for Transient Simulations of Cooling Systems with NonUniform Temperature and Flow Boundaries Extracted from a 3D CFD Solution, in: SAE Tech. Pap. 2015-01$0337,2015$.

[26] R. Yuan, S. Sivasankaran, N. Dutta, W. Jansen, K. Ebrahimi, Numerical investigation of buoyancy-driven heat 
transfer within engine bay environment during thermal soak, Appl. Therm. Eng., (2019) 114525.

[27] R. Yuan, C. Price, R. Kasurkar, M. Spenley, N. Dutta, K. Ebrahimi, Numerical Investigation of Heat Retention and Warm-Up with Thermal Encapsulation of Powertrain, SAE Tech. Pap. 2020-01-0158, (2020) 1-8.

[28] T. Fletcher, N. Kalantzis, A. Ahmedov, R. Yuan, K. Ebrahimi, N. Dutta, C. Price, Holistic Thermal Energy Modelling For Full Hybrid Electric Vehicles (HEVs), SAE Tech. Pap. 2020-01-0151, (2020) 1-15.

[29] N. Kalantzis, T. Fletcher, A. Pezouvanis, K. Ebrahimi, M. Cary, B. Lygoe, Modelling Environment for Holistic Vehicle Simulation, in: K. Ebrahimi (Ed.), 4th Bienn. Int. Conf. Powertrain Model. Control (PMC 2018), Loughborough, 2018: p. 120.

[30] T. Fletcher, N. Kalantzis, M. Cary, B. Lygoe, A. Pezouvanis, K. Ebrahimi, Automated Model Based Engine Calibration Procedure using Co-Simulation, in: K. Ebrahimi (Ed.), 4th Bienn. Int. Conf. Powertrain Model. Control (PMC 2018), Loughborough, 2018: p. 118.

[31] N. Kalantzis, T. Fletcher, A. Ahmedov, R. Yuan, A. Pezouvanis, K. Ebrahimi, S. Shojaei, R. Osborne, CoSimulation Methods for Holistic Vehicle Design: A Comparison, SAE Tech. Pap. 2020-01-1017, (2020) 1-13.

[32] G.J. Marshall, C.P. Mahony, M.J. Rhodes, S.R. Daniewicz, N. Tsolas, S.M. Thompson, Thermal Management of Vehicle Cabins, External Surfaces, and Onboard Electronics: An Overview, Engineering, (2019).

[33] W. Enang, C. Bannister, Modelling and control of hybrid electric vehicles (A comprehensive review), Renew. Sustain. Energy Rev., 74 (2017) 1210-1239.

[34] P. Mock, J. Kühlwein, U. Tietge, V. Franco, A. Bandivadekar, J. German, The WLTP: How a new test procedure for cars will affect fuel consumption values in the EU, ICCT White Pap., 2014 (2014) 1-20.

[35] H.C. Watson, Vehicle Driving Patterns and Measurement Methods for Energy and Emissions Assessment, Bur. Transp. Econ., (1978).

[36] C. Brace, Engine modelling and optimisation for RDE, FPC2015 Futur. Powertrain Conf., (2014).

[37] I. Taymaz, M. Benli, Emissions and fuel economy for a hybrid vehicle, Fuel, 115 (2014) 812-817.

[38] T. Fletcher, R.H. Thring, M. Watkinson, I. Staffell, Comparison of Fuel Consumption and Fuel Cell Degradation Using an Optimised Controller, in: ECS Trans., 2016: pp. 85-97.

[39] Society of Automotive Engineers, SAE J1711, Recommended Practice for Measuring Exhaust Emissions and Fuel Economy of Hybrid-Electric Vehicles, 2010.

[40] C. Manzie, P. Dewangan, G. Corde, O. Grondin, A. Sciarretta, State of charge management for plug in hybrid electric vehicles with uncertain distance to recharge, in: 2013 9th Asian Control Conf., IEEE, 2013: pp. 1-6.

[41] H. Liu, X. Li, W. Wang, L. Han, C. Xiang, Markov velocity predictor and radial basis function neural networkbased real-time energy management strategy for plug-in hybrid electric vehicles, Energy, 152 (2018) 427-444.

[42] Y. Zhang, H. El-Merhubi, B. Lefort, L. Le Moyne, H.J. Curran, A. Kéromnès, Probing the low-temperature chemistry of ethanol via the addition of dimethyl ether, Combust. Flame, 190 (2018) 74-86.

[43] S.J. Moura, J.L. Stein, H.K. Fathy, Battery-Health Conscious Power Management in Plug-In Hybrid Electric Vehicles via Electrochemical Modeling and Stochastic Control, IEEE Trans. Control Syst. Technol., 21 (2013) 679-694.

[44] T. Fletcher, R. Thring, M. Watkinson, An Energy Management Strategy to concurrently optimise fuel consumption \&amp; PEM fuel cell lifetime in a hybrid vehicle, Int. J. Hydrogen Energy, 41 (2016) 2150321515 .

[45] M. Roozegar, J. Angeles, The optimal gear-shifting for a multi-speed transmission system for electric vehicles, Mech. Mach. Theory, 116 (2017) 1-13.

[46] G. Zhang, W. Chen, Q. Li, Modeling, optimization and control of a FC/battery hybrid locomotive based on ADVISOR, Int. J. Hydrogen Energy, 42 (2017) 18568-18583. 
[47] K.B.B. Wipke, M.R.R. Cuddy, S.D.D. Burch, ADVISOR 21: A User-friendly Advanced Powertrain Simulation using a Combined Backward/Forward Approach, IEEE Trans. Veh. Technol., 48 (1999) 1751-1761.

[48] M. Montazeri-Gh, M. Mahmoodi-K, Optimized predictive energy management of plug-in hybrid electric vehicle based on traffic condition, J. Clean. Prod., 139 (2016) 935-948.

[49] T.P. Fletcher, Optimal energy management strategy for a fuel cell hybrid electric vehicle, Loughborough University (2017). Thesis, https://hdl.handle.net/2134/25567

[50] Q. Zhou, W. Zhang, S. Cash, O. Olatunbosun, H. Xu, G. Lu, Intelligent sizing of a series hybrid electric powertrain system based on Chaos-enhanced accelerated particle swarm optimization, Appl. Energy, 189 (2017) 588601.

[51] B. V. Padmarajan, A. McGordon, P.A. Jennings, Blended Rule-Based Energy Management for PHEV: System Structure and Strategy, IEEE Trans. Veh. Technol., 65 (2016) 8757-8762.

[52] C. Cheng, A. McGordon, R.P. Jones, P.A. Jennings, Development of a comprehensive and flexible forward dynamic powertrain simulation tool for various hybrid electric vehicle architectures, Proc. Inst. Mech. Eng. Part D J. Automob. Eng., 226 (2012) 385-398.

[53] S. Shojaei, A. McGordon, S. Robinson, J. Marco, P. Jennings, Developing a model for analysis of the cooling loads of a hybrid electric vehicle by using co-simulations of verified submodels, Proc. Inst. Mech. Eng. Part D J. Automob. Eng., 232 (2018) 766-784.

[54] M. Stifter, E. Widl, F. Andren, A. Elsheikh, T. Strasser, P. Palensky, Co-simulation of components, controls and power systems based on open source software, in: 2013 IEEE Power Energy Soc. Gen. Meet., IEEE, 2013: pp. 15.

[55] C. Vagg, Optimal Control of Hybrid Electric Vehicles for Real-World Driving Patterns, University of Bath, Thesis, 2015.

[56] N. Murgovski, M. Grahn, L. Mardh Johannesson, T. McKelvey, Automated Engine Calibration of Hybrid Electric Vehicles, IEEE Trans. Control Syst. Technol., 23 (2015) 1063-1074.

[57] J. Ruan, P. Walker, N. Zhang, A comparative study energy consumption and costs of battery electric vehicle transmissions, Appl. Energy, 165 (2016) 119-134.

[58] C. Vagg, S. Akehurst, C.J. Brace, L. Ash, Stochastic Dynamic Programming in the Real-World Control of Hybrid Electric Vehicles, IEEE Trans. Control Syst. Technol., 24 (2016) 853-866.

[59] Y. Tian, J. Ruan, N. Zhang, J. Wu, P. Walker, Modelling and control of a novel two-speed transmission for electric vehicles, Mech. Mach. Theory, 127 (2018) 13-32.

[60] Gamma Technologies, Vehicle Driveline and HEV Application Manual, 2018.

[61] C. Musardo, G. Rizzoni, Y. Guezennec, B. Staccia, A-ECMS: An Adaptive Algorithm for Hybrid Electric Vehicle Energy Management, Eur. J. Control, 11 (2005) 509-524.

[62] G. Mohan, F. Assadian, S. Longo, An Optimization Framework for Comparative Analysis of Multiple Vehicle Powertrains, Energies, 6 (2013) 1-31.

[63] S. Shojaei, D. Strickland, D. Scott, M.R. Tucker, G. Kirkpatrick, B. Price, S. Luke, J. Richmond, A. Shojaei, D. Strickland, D. Scott, M.R. Tucker, G. Kirkpatrick, B. Price, S. Luke, J. Richmond, Powertrain optimisation in a hybrid electric bus, in: 2012 IEEE Veh. Power Propuls. Conf., IEEE, Seoul, South Korea, 2012: pp. 857-862.

[64] T. Nüesch, A. Cerofolini, G. Mancini, N. Cavina, C. Onder, L. Guzzella, Equivalent Consumption Minimization Strategy for the Control of Real Driving NOx Emissions of a Diesel Hybrid Electric Vehicle, Energies, 7 (2014) $3148-3178$.

[65] A. Walker, A. McGordon, G. Hannis, A. Picarelli, J. Breddy, S. Carter, A. Vinsome, P. Jennings, M. Dempsey, M. Willows, A Novel Structure for Comprehensive HEV Powertrain Modelling, in: 2006 IEEE Veh. Power 
Propuls. Conf., IEEE, 2006: pp. 1-5.

[66] L. Guo, B. Gao, Y. Gao, H. Chen, Optimal Energy Management for HEVs in Eco-Driving Applications Using Bi-Level MPC, IEEE Trans. Intell. Transp. Syst., 18 (2017) 2153-2162.

[67] B. Zhong, B. Deng, H. Zhao, Simulation Model and Method for Active Torsional Vibration Control of an HEV, Appl. Sci., 9 (2018) 34.

[68] D. Sinoquet, G. Rousseau, Y. Milhau, Design optimization and optimal control for hybrid vehicles, Optim. Eng., 12 (2011) 199-213.

[69] X. Li, S.A. Evangelou, Torque-Leveling Threshold-Changing Rule-Based Control for Parallel Hybrid Electric Vehicles, IEEE Trans. Veh. Technol., 68 (2019) 6509-6523.

[70] J. Fleming, X. Yan, C. Allison, N. Stanton, R. Lot, Driver Modeling and Implementation of a Fuel-Saving ADAS, in: 2018 IEEE Int. Conf. Syst. Man, Cybern., IEEE, 2018: pp. 1233-1238.

[71] J. Xu, H.-B. Shu, Y.-M. Shao, Modeling of Driver Behavior on Trajectory-Speed Decision Making in Minor Traffic Roadways With Complex Features, IEEE Trans. Intell. Transp. Syst., 20 (2019) 41-53.

[72] E. Hellstrom, M. Jankovic, A driver model for velocity tracking with look-ahead, in: 2015 Am. Control Conf., IEEE, 2015: pp. 3342-3347.

[73] A. Vdovin, Cooling performance simulations in GT-Suite, Chalmers University of Technology, 2010.

[74] L. Xu, C.D. Mueller, J. Li, M. Ouyang, Z. Hu, Multi-objective component sizing based on optimal energy management strategy of fuel cell electric vehicles, Appl. Energy, 157 (2015) 664-674.

[75] Z. Song, X. Zhang, J. Li, H. Hofmann, M. Ouyang, J. Du, Component sizing optimization of plug-in hybrid electric vehicles with the hybrid energy storage system, Energy, 144 (2018) 393-403.

[76] Xiaowu Zhang, Huei Peng, Jing Sun, A Near-Optimal Power Management Strategy for Rapid Component Sizing of Multimode Power Split Hybrid Vehicles, IEEE Trans. Control Syst. Technol., 23 (2015) 609-618.

[77] N.R. Agarwal, Modeling, Validation and Analysis of an Advanced Thermal Management System for Conventional Automotive Powertrains, Electronic Thesis or Dissertation. Ohio State University, 2012. https://etd.ohiolink.edu/.

[78] N. Keuth, H. Altenstrasser, A. Kunzfeld, E. Martini, Advanced Methods for Calibration and Validation of DieselECU Models Using Emission and Fuel Consumption Optimization and Prediction During Dynamic Warm Up Tests (EDC), SAE Tech. Pap., 2013-26-0113, 2013, https://doi.org/10.4271/2013-26-0113.

[79] X. Tang, D. Zhang, T. Liu, A. Khajepour, H. Yu, H. Wang, Research on the energy control of a dual-motor hybrid vehicle during engine start-stop process, Energy, 166 (2019) 1181-1193.

[80] Dezong Zhao, R. Stobart, Guangyu Dong, E. Winward, Real-Time Energy Management for Diesel Heavy Duty Hybrid Electric Vehicles, IEEE Trans. Control Syst. Technol., 23 (2015) 829-841.

[81] F. Vidal-Naquet, G. Zito, Adapted optimal energy management strategy for drivability, in: 2012 IEEE Veh. Power Propuls. Conf., IEEE, 2012: pp. 358-363.

[82] R. Steffan, P. Hofmann, B. Geringer, Potentials of a 48 Volt Belt-Starter-Generator in the Powertrain of an UltraLight Vehicle, in: SAE Tech. Pap., SAE International, 2015.

[83] S. Lee, J. Cherry, M. Safoutin, A. Neam, J. McDonald, K. Newman, Modeling and Controls Development of 48 v Mild Hybrid Electric Vehicles, in: SAE Tech. Pap., SAE International, 2018.

[84] B. Gao, K. Svancara, A. Walker, D. Kok, M. Conen, D. Kees, Development of a BISG micro-hybrid system, in: SAE Tech. Pap., 2009-01-1330, 2009, https://doi.org/10.4271/2009-01-1330.

[85] I.-A. Viorel, L. Szabó, L. Löwenstein, C. Şteţ, Integrated starter-generators for automotive applications, Acta Electroteh., 45 (2004).

[86] B. Lan, Design Simulation and Experiments on Electrical Machines for Integrated Starter-Generator 
Applications, University of Sheffield, 2018.

[87] R.K. Sharma, P. Verma, A. Yadav, M. Khan, Development of Real Time Mild Hybrid Simulation Model using Battery in Loop, in: SAE Tech. Pap., SAE International, 2016.

[88] T.Q. Dinh, J. Marco, D. Greenwood, L. Harper, D. Corrochano, Powertrain Modelling and Engine Start Control of Construction Machines, in: K. Ebrahimi (Ed.), 3rd Bienn. Int. Conf. Powertrain Model. Control (PMC 2016), Loughborough, 2016.

[89] A.D. Wearing, J. Haybittle, R. Bao, J.W. Baxter, C. Rouaud, O. Taskin, Development of high power 48V Powertrain Components for Mild Hybrid Light Duty Vehicle Applications, in: 2018 IEEE Energy Convers. Congr. Expo. ECCE 2018, Institute of Electrical and Electronics Engineers Inc., 2018: pp. 3893-3900.

[90] M. Awadallah, P. Tawadros, P. Walker, N. Zhang, Dynamic modelling and simulation of a manual transmission based mild hybrid vehicle, Mech. Mach. Theory, 112 (2017) 218-239.

[91] Y. Wang, Q. Gao, T. Zhang, G. Wang, Z. Jiang, Y. Li, Advances in Integrated Vehicle Thermal Management and Numerical Simulation, Energies, 10 (2017) 1636.

[92] A. Traussnig, H. Petutschnig, A. Ennemoser, M. Stolz, M. Tizianel, Vehicle Thermal Management Simulation Method Integrated in the Development Process from Scratch to Prototype, in: SAE Tech. Pap. 2014-01-0668, SAE International, 2014.

[93] B. Song, J. Kwon, Y. Kim, Air Conditioning System Sizing for Pure Electric Vehicle, World Electr. Veh. J., 7 (2015) 407-413.

[94] D. Leighton, Combined Fluid Loop Thermal Management for Electric Drive Vehicle Range Improvement, SAE Int. J. Passeng. Cars - Mech. Syst., 8 (2015) 711-720.

[95] O. Karabasoglu, J. Michalek, Influence of driving patterns on life cycle cost and emissions of hybrid and plug-in electric vehicle powertrains, Energy Policy, 60 (2013) 445-461.

[96] V.H. Johnson, K.B. Wipke, D.J. Rausen, HEV control strategy for real-time optimization of fuel economy and emissions, in: SAE Tech. Pap., 2000.

[97] D. Kum, H. Peng, N.K. Bucknor, Optimal energy and catalyst temperature management of plug-in hybrid electric vehicles for minimum fuel consumption and tail-pipe emissions, IEEE Trans. Control Syst. Technol., 21 (2013) $14-26$.

[98] C.A. Henry, S.T. Eakle, B. Zavala, Physical Exhaust Gas Simulation System for Emissions Development, MTZ Ind., 8 (2018) 44-48.

[99] S. Dhingra, P. Quinney, Vehicle-In-Loop Testing, 2019.

[100] J.C. Peyton Jones, J.B. Roberts, P. Bernard, R.A. Jackson, A simplified model for the dynamics of a three-way catalytic converter, in: SAE Tech. Pap., 2000-01-0652, 2000, https://doi.org/10.4271/2000-01-0652.

[101] M. Apolloni, Derivation of a 1-D thermal model of vehicle underhood temperatures on the basis of test data using an evolutionary algorithm, ETH Zurich, 2006.

[102] W. Puntigam, J. Balic, R. Almbauer, J. Hager, Transient Co-Simulation of Comprehensive Vehicle Models by Time Dependent Coupling, in: SAE Tech. Pap. 2006-01-1604, SAE International, 2006.

[103] S.C. Pang, M.A. Kalam, H.H. Masjuki, I.A. Badruddin, M.A. Hazrat, Design Improvements of Engine Cooling System Using CFD and 1D Thermo-Fluid Model: Medium Driving Speed and Keyed-Off Conditions, Eng. eTransaction, 7 (2012) 127-134.

[104] B.B. Minovski, L. Lofdahl, Study of software integration for transient simulation of future cooling system for heavy truck application, SAE Tech. Pap., 1 (2014).

[105] P. Dinakar, G. Rajeeve, Modelling and Simulation of Cooling Systems for BEV High Voltage Battery, Chalmers University of Technology, Thesis, 2016. https://hdl.handle.net/20.500.12380/242083 
[106] T. Kiss, J. Lustbader, D. Leighton, Modeling of an Electric Vehicle Thermal Management System in MATLAB/Simulink, in: SAE Tech. Pap. 2015-01-1708, SAE International, 2015.

[107] P. Barasa, Y. Tian, S. Hardes, S. Owlia, P. Limaye, D. Bailey, T. Sehgal, Virtual Engine, Controls, and Calibration Development in Automated Co-Simulation Environment, in: SAE Tech. Pap. 2016-01-0090, SAE International, 2016.

[108] L.R. Uppalapati, B. Vernham, Y. Wei, Development and validation of engine calibration using 1d predictive models, in: SAE Tech. Pap., SAE International, 2019.

[109] N. Lorenz, G. Offner, O. Knaus, Thermal Analysis of Hydrodynamic Lubricated Journal Bearings in Internal Combustion Engines, Paper presented at 3rd Bienn. Int. Conf. Powertrain Model. Control (PMC 2016), Loughborough, 2016.

[110] M. Cavalli, G. Lavacchielli, R. Tonelli, G. Nicoletto, E. Riva, Comparison of analytical and multibody dynamic approaches in the study of a V6 engine piston, in: K. Ebrahimi (Ed.), 3rd Bienn. Int. Conf. Powertrain Model. Control (PMC 2016), Loughborough, 2016.

[111] V. Elisaus, M. Mohammadpour, S. Theodossiades, H. Rahnejat, Tribological Investigation of Truncated thermoElastohydrodynamic Elliptical Point Contacts in High Performance Transmissions, in: K. Ebrahimi (Ed.), 3rd Bienn. Int. Conf. Powertrain Model. Control (PMC 2016), Loughborough, 2016.

[112] B. Minovski, J. Andrić, L. Löfdahl, P. Gullberg, A numerical investigation of thermal engine encapsulation concept for a passenger vehicle and its effect on fuel consumption, Proc. Inst. Mech. Eng. Part D J. Automob. Eng., 233 (2019) 557-571.

[113] M.R. Khan, M.J. Swierczynski, S.K. Kær, Towards an Ultimate Battery Thermal Management System: A Review, Batteries, 3 (2017) 9.

[114] P. Lu, Q. Gao, Y. Wang, The simulation methods based on 1D/3D collaborative computing for the vehicle integrated thermal management, Appl. Therm. Eng., 104 (2016) 42-53.

[115] C. Stroh, R. Reitbauer, J. Hanner, Increasing the reliability of designing a cooling package by applying joint 1D/3D simulation, in: SAE Tech. Pap., 2006-01-1571, 2006, https://doi.org/10.4271/2006-01-1571.

[116] D. Chalet, M. Lesage, M. Cormerais, T. Marimbordes, Nodal modelling for advanced thermal-management of internal combustion engine, Appl. Energy, 190 (2017) 99-113.

[117] S. Loghavi, Modeling, Control Analysis, and Multi-Physics Co-Simulation Supporting High-Performance Hybrid-Electric Vehicles, Georgia Institute of Technology, Thesis, 2017, http://hdl.handle.net/1853/58751.

[118] P. Liu, D. Li, Issues and factors of train air-conditioning system design and operation, Energy Systems Laboratory (http://esl.tamu.edu); Texas A\&M University (http://www.tamu.edu). Available electronically from http : / /hdl .handle .net/1969.1/5247.

[119] S.K. Wang, Handbook of Air Conditioning and Refrigeration, McGraw-Hill Professional, Beijing, 2010.

[120] K. Martín, I. Flores, C. Escudero, A. Apaolaza, J.M. Sala, Methodology for the calculation of response factors through experimental tests and validation with simulation, Energy Build., 42 (2010) 461-467.

[121] G.P. Mitalas, D.G. Stephenson, Cooling Load Calculations by Thermal Response Factor Method, Division of Building Research, National Research Council Canada, 1967.

https://nrc-publications.canada.ca/eng/view/ft/?id=0a164630-2bf0-42b9-a312-695f85ec8a49.

[122] D. Fisher, Application of Conduction Transfer Functions and Periodic Response Factors in Cooling Load Calculation Procedures, ASHRAE Trans., 110 (2004).

[123] O. Solmaz, M. Ozgoren, M.H. Aksoy, Hourly cooling load prediction of a vehicle in the southern region of Turkey by Artificial Neural Network, Energy Convers. Manag., 82 (2014) 177-187.

[124] D. Marcos, F.J. Pino, C. Bordons, J.J. Guerra, The development and validation of a thermal model for the cabin 
of a vehicle, Appl. Therm. Eng., 66 (2014) 646-656.

[125] B. Torregrosa-Jaime, F. Bjurling, J.M. Corberán, F. Di Sciullo, J. Payá, Transient thermal model of a vehicle’s cabin validated under variable ambient conditions, Appl. Therm. Eng., 75 (2015) 45-53.

[126] J. Pokorny, J. Fiser, M. Jicha, Operational Heat Balance Model with Parameterized Geometry for the Prediction of Car Cabin Heat Loads, Int. J. Vent., 11 (2013) 393-406.

[127] Commission Regulation (EU) 2017/1151 of 1 June 2017 supplementing Regulation (EC) No 715/2007 of the European Parliament and of the Council on type-approval of motor vehicles with respect to emissions from light passenger and commercial vehicles (Euro 5 and Euro 6) and on access to vehicle repair and maintenance information, amending Directive 2007/46/EC of the European Parliament and of the Council, Commission Regulation (EC) No 692/2008 and Commission Regulation (EU) No 1230/2012 and repealing, Https://Webarchive.Nationalarchives.Gov.Uk/Eu-Exit/Https://Eur-Lex.Europa.Eu/LegalContent/EN/TXT/?Uri=CELEX:02017R1151-20190101, (n.d.).

[128] D. Petley, W. Jansen, B. Wicksteed, D. Caprioli, T. Bürgin, Pre-development validation of an engine mounted encapsulation approach on SUV vehicle as „Eco-Innovation“ by means of EU Regulation 725/2011, in: Bargende M., Reuss HC., Wiedemann J. 14. Int. Stuttgarter Symp. Proceedings. Springer Vieweg, Wiesbad., 2014.

[129] Exa Corp., PowerFLOW User's Guide 30, Exa Corp., Lexington, MA, 1998.

[130] B. Dexter, et al., Powertrain Encapsulation for Low CO2 Emissions, referred in the press article 'Ricardo shares insights on thermal optimization of electrified and conventional powertrains', in Vehicle Thermal Management Systems conference (VTMS 14), London, 5-6 June 2019, 2019.

[131] R. Yuan, et al., Heat retention analysis with thermal encapsulation of powertrain under natural soak environment, Int. J. Heat Mass Transf., 118940 (2019).

[132] K. Robinson, N.A.F. Campbell, J.G. Hawley, D.G. Tilley, A review of precision engine cooling, in: SAE Tech. Pap., 1999.

[133] P. Setlur, J.R. Wagner, D.M. Dawson, E. Marotta, An advanced engine thermal management system: Nonlinear control and test, IEEE/ASME Trans. Mechatronics, 10 (2005) 210-220.

[134] N.S. Ap, P. Guerrero, P. Jouanny, Influence of fan system electric power on the heat performance of engine cooling module, in: SAE Tech. Pap., 2003.

[135] J. Wagner, I. Paradis, E. Marotta, D. Dawson, Enhanced automotive engine cooling systems - A mechatronics approach, Int. J. Veh. Des., 28 (2002) 214-240.

[136] T. Mitchell, M. Salah, J. Wagner, D. Dawson, Automotive thermostat valve configurations: Enhanced warm-up performance, J. Dyn. Syst. Meas. Control. Trans. ASME, 131 (2009) 1-7.

[137] K.B. Kim, K.W. Choi, K.H. Lee, K.S. Lee, Active coolant control strategies in automotive engines, Int. J. Automot. Technol., 11 (2010) 767-772.

[138] M. Chanfreau, B. Gessier, A. Farkh, P.Y. Geels, The need for an electrical water valve in a THErmal management intelligent system (THEMISTM), in: SAE Tech. Pap., 2003.

[139] P.M. Lindh, I. Petrov, R.S. Semken, M. Niemela, J.J. Pyrhonen, L. Aarniovuori, T. Vaimann, A. Kallaste, Direct liquid cooling in low-power electrical machines: Proof-of-concept, IEEE Trans. Energy Convers., 31 (2016) $1257-1266$.

[140] H. Teng, Y. Ma, K. Yeow, M. Thelliez, An Analysis of a Lithium-ion Battery System with Indirect Air Cooling and Warm-Up, SAE Int. J. Passeng. Cars - Mech. Syst., 4 (2011) 1343-1357.

[141] T. Nakahama, K. Suzuki, S. Hashidume, F. Ishihashi, M. Hirata, Cooling airflow in unidirectional ventilated open-type motor for electric vehicles, IEEE Trans. Energy Convers., 21 (2006) 645-651.

[142] A. Pesaran, A. Vlahinos, T. Stuart, Cooling and Preheating of Batteries in Hybrid Electric Vehicles, in: 6th 
ASME-JSME Thermal Engineering Joint Conference, 2003, TED-AJ03-633.

[143] C. Zhang, K. Li, J. Deng, Real-time estimation of battery internal temperature based on a simplified thermoelectric model, J. Power Sources, 302 (2016) 146-154.

[144] A. Tourani, P. White, P. Ivey, Analysis of electric and thermal behaviour of lithium-ion cells in realistic driving cycles, J. Power Sources, 268 (2014) 301-314.

[145] Y. Zhang, C.Y. Wang, X. Tang, Cycling degradation of an automotive LiFePO4 lithium-ion battery, J. Power Sources, 196 (2011) 1513-1520.

[146] S.B. Peterson, J. Apt, J.F. Whitacre, Lithium-ion battery cell degradation resulting from realistic vehicle and vehicle-to-grid utilization, J. Power Sources, 195 (2010) 2385-2392.

[147] J. Vetter, P. Novák, M.R. Wagner, C. Veit, K.C. Möller, J.O. Besenhard, M. Winter, M. Wohlfahrt-Mehrens, C. Vogler, A. Hammouche, Ageing mechanisms in lithium-ion batteries, J. Power Sources, 147 (2005) 269-281.

[148] W. Li, J. Sun, Numerical simulation and analysis of transport air conditioning system integrated with passenger compartment, Appl. Therm. Eng., 50 (2013) 37-45.

[149] T. Kiss, L. Chaney, J. Meyer, A new automotive air conditioning system simulation tool developed in MATLAB/Simulink, (2013).

[150] J. Jeffs, A. McGordon, A. Picarelli, S. Robinson, W.D. Widanage, System level heat pump model for investigations into thermal management of electric vehicles at low temperatures, Proc. 13th Int. Model. Conf. Regensburg, Ger. March 4-6, 2019, 157 (2019) 107-116.

[151] W. Chen, M. Klomp, S. Ran, Real-time co-simulation method study for vehicle steering and chassis system, IFAC-PapersOnLine, 51 (2018) 273-278.

[152] M. Maharun, M. Bin Baharom, M.S. Mohd, Modelling and control of 4wd parallel split hybrid electric vehicle converted from a conventional vehicle, World J. Model. Simul., 9 (2013) 47-58.

[153] J.J. Eckert, F.M. Santiciolli, E. dos S. Costa, F.C. Corrêa, H.J. Dionísio, F.G. Dedini, Vehicle gear shifting cosimulation to optimize performance and fuel consumption in the Brazilian standard urban driving cycle, in: Blucher Eng. Proc., 2014: pp. 615-631.

[154] G. Li, T. Wang, R. Zhang, E. Al., An improved optimal slip ratio prediction considering tyre inflation pressure changes, J. Control Sci. Eng., (2015).

[155] F. Xie, J. Wang, Y. Wang, Modelling and co-simulation based on AMESim and Simulink for light passenger car with dual state CVT, Procedia Eng., 16 (2011) 363-368.

[156] S. Li, L. Zhao, C. Yang, Co-simulation study for fuzzy ESP control strategy on vehicle, Open Mech. Eng. J., 8 (2014) 682-688.

[157] O. Özener, L. Allouchery, Istanbul metrobus line fuel consumption optimisation via 3D road model by using AVL cruise \& IPG truck marker co-simualation, Int. J. Adv. Automot. Technol., 1 (2017) 100-104.

[158] A. Karvonen, T. Thiringer, Co-simulation and harmonic analysis of a hybrid vehicle traction system, in: 2015 IEEE Veh. Power Propuls. Conf., 2015: pp. 1-6.

[159] T. Blochwitz, M. Otter, M. Arnold, et al., The functional mockup interface for tool independent exchange of simulation models, in Proc. 8th Int. Model. Conf., 2011, pp. 105-114.

[160] R. Hallqvist, R. Braun, and P. Krus, Early insights on FMI-based co-simulation of aircraft vehicle systems, in Proc. 15th Scand. Int. Conf. Fluid Power, 2017, Linköping, Sweden, vol. 144, pp. 262-270.

[161] T. Blockwitz, M. Otter, J. Åkesson, et al., Functional mockup interface 2.0: the standard for tool independent exchange of simulation models, in Proc. 9th Int. Model. Conf. 2012, Munich, Ger., vol. 76, pp. 173-184. 
[162] A.W.M. (Jos) van Schijndel, A review of the application of SimuLink S-functions to multi domain modelling and building simulation, Journal of Building Performance Simulation, 2014, 7:3, 165-178, DOI: 10.1080/19401493.2013.804122.

[163] M. Honek, J. Csamb'al, S. Wojnar, M. Kopavcka, P. Simoncicand and M. Lauko, Rapid control prototyping system dSPACE used for control of combustion engine processes, ARPN Journals, 2015. Available electronically from https://www2.humusoft.cz/www/papers/tcb10/039_honek.pdf

[164] T. He, L. Peng, Application of neuron adaptive PID on DSPACE in double loop DC motor control system, in Int. Conf. Comput. Control Ind. Eng. CCIE (2010), vol. 2, pp. 257-260.

[165] D. Siegele, F. Ochs, and W. Feist, Modelling and simulation of façade integrated active components with MATLAB/SIMULINK, in Fifth German-Austrian IBPSA Conference, Aachen, Germany, BauSIM 2014, pp. 198-205.

[166] S. Zhao, L. Zhu, Cruise control system based on joint simulation of CarSim and Simulink, in Open Access Library Journal, 5, 1-8 (2018), doi: 10.4236/oalib.1104724.

[167] G. Park, B. Son, D. Kum, S. Lee, and S. Kwak, Dynamic modeling and simulation for Battery Electric Vehicles under inverter fault conditions, Appl. Mech. Mater., vol. 110-116, pp. 3007-3015, 2012.

[168] P. Innerwinkler, G. Stettinger, R. Weissnegger, C. Derse, E. Aydemir and J. Zaya, Modular co-simulation architecture plan, 2018, report, in ART-04-2016 - Safety and end-user acceptance aspects of road automation in the transition period, H2020-ART-2016-2017, available electronically from http://www.trustvehicle.eu/wpcontent/uploads/2018/07/TrustVehicle_D3.2_Final.pdf.

[169] K. Hübner, M. Neubauer, R. Protzmann, et al. Architecture and interface specification of the Co-Simulation environment, 2018, report, INFRAMIX - Road INFRAstructure ready for MIXed vehicle traffic flows, available electronically from, https://inframix.eu/wpcontent/uploads/D2.2_architecture_and_interface_specification_co_simulation.pdf.

[170] A. Piovano, L. Lorefice and G. Scantamburlo, Modelling of car cabin thermal behaviour during cool down using an advanced cfd/thermal approach, SAE Technical Paper 2016-01-0213, 2016, doi:10.4271/2016-01-0213.

[171] S. Sen and M. Selokar, Numerical simulation and validation of cabin aiming and cool-down of a passenger car, SAE Int. J. Passeng. Cars - Mech. Syst. 9(1):2016, doi:10.4271/2016-01-0251. 